\title{
The Role of Large-Scale Moistening by Adiabatic Lifting in the Madden-Julian Oscillation Convective Onset
}

\author{
Chelsea E. Snide, ${ }^{a}$ Ángel F. Adames, ${ }^{a}$ Scott W. Powell, ${ }^{b}$ And Víctor C. Mayta ${ }^{\mathrm{c}}$ \\ ${ }^{a}$ Department of Atmospheric and Oceanic Sciences, University of Wisconsin, Madison, Wisconsin \\ ${ }^{\mathrm{b}}$ Department of Meteorology, Naval Postgraduate School, Monterey, California \\ ${ }^{\mathrm{c}}$ Department of Climate and Space Sciences and Engineering, University of Michigan, Ann Arbor, Michigan
}

(Manuscript received 22 April 2021, in final form 24 September 2021)

\begin{abstract}
The initiation of the Madden-Julian oscillation over the Indian Ocean is examined through the use of a moisture budget that applies a version of the weak temperature gradient (WTG) approximation that does not neglect dry adiabatic vertical motions. Examination of this budget in ERA-Interim reveals that horizontal moisture advection and vertical advection by dry adiabatic lifting govern the moistening of the troposphere for both primary and successive MJO initiation events. For both types of initiation events, horizontal moisture advection peaks prior to the maximum moisture tendency, while dry adiabatic lifting peaks after the maximum moisture tendency. Once convection initiates, moisture is maintained by anomalous radiative and adiabatic lifting. The dry adiabatic lifting during successive MJO initiation is attributed to the return of the circumnavigating circulation from a previous MJO event, while in primary events the planetaryscale circulation appears to originate over South America. Examination of the same budget with data from the DYNAMO northern sounding array shows that adiabatic lifting contributes significantly to MJO maintenance, with a contribution that is comparable to that of surface heat fluxes. However, results from the DYNAMO data disagree with those from ERAInterim over the importance of adiabatic lifting to the moistening of the troposphere prior to the onset of convection. In spite of these differences, the results from the two datasets show that small departures from WTG balance in the form of dry adiabatic motions cannot be neglected when considering MJO convective onset.
\end{abstract}

KEYWORDS: Atmospheric circulation; Deep convection; Madden-Julian oscillation; Moisture/moisture budget; Tropical variability

\section{Introduction}

The Madden-Julian oscillation [MJO; after Madden and Julian $(1971,1972)]$ is an important mode of tropical intraseasonal variability. Studies often describe it as an envelope of convection thousands of kilometers across, coupled with planetary-scale circulations (Kiladis et al. 2005; Hendon and Salby 1994). The convection usually develops over the western Indian Ocean in a process known as MJO initiation. Once initiated, the coupled convection and circulation features progress eastward at a rate of $5 \mathrm{~m} \mathrm{~s}^{-1}$ over the warm water of the Indo-Pacific warm pool $\left(60^{\circ} \mathrm{E}-180^{\circ}\right)$ (Zhang 2005). The convection often decays as it reaches the date line, primarily due to cool sea surface temperatures, while the circulation and pressure oscillations continue propagating eastward at roughly 20-30 $\mathrm{m} \mathrm{s}^{-1}$ (Hendon and Salby 1994; Milliff and Madden 1996; Sobel and Kim 2012). The cycle of the MJO, including both the slowly propagating convective signal over the warm pool and the fast circumnavigating signal, has profound impacts on the global circulation (Zhang 2013) and is an important source of predictability at the intraseasonal time scale (Kim et al. 2018; Jiang et al. 2020).

A feature of the MJO cycle is that the circulation of a previous $\mathrm{MJO}$ event often returns to the warm pool, signaling the initiation of a "successive" convectively active phase of the MJO (Matthews 2008; Powell 2017). In other cases, the MJO

Corresponding author: Chelsea E. Snide, snide@wisc.edu becomes active in the absence of a circumnavigating signal, a process that is referred to as primary initiation (Matthews 2008; Straub 2013). The processes underlying both primary and successive MJO initiation are not well understood and pose an outstanding issue for simulating the MJO in global circulation models (GCMs) (Kim et al. 2018).

Various hypotheses have been proposed to understand the dynamics underlying MJO convective initiation. For successive MJO initiation, large-scale horizontal advection of moisture from the Maritime Continent has been suggested as the main moistening process (Zhao et al. 2013; Wolding 2013; Li et al. 2015; Mei et al. 2015). Other studies have argued that the key process is free-tropospheric moistening by anomalous dry adiabatic lifting that results from the return of the circumnavigating signal to the Indian Ocean (Kikuchi and Takayabu 2003; Powell and Houze 2015; Haertel et al. 2015; Powell 2016; Chen and Zhang 2019). These dry adiabatic motions are small, on the order of $1 \mathrm{~mm} \mathrm{~s}^{-1}$, and are associated with temperature fluctuations on the order of $\sim 0.3 \mathrm{~K}$ that have a maximum amplitude between 300 and $600 \mathrm{hPa}$. In spite of its small amplitude, anomalous dry adiabatic lifting can suppress the background environmental subsidence, effectively moistening the free troposphere. This lifting also increases the lower tropospheric lapse rate, so that convection becomes more likely to grow out of the boundary layer and moisten the free troposphere, allowing for extensive mesoscale regions of convection to occur (Powell and Houze 2015; Powell 2016).

For primary initiation it is argued that moistening in the lower troposphere over the Indian Ocean through nonlinear moisture 
advection is present prior to convective onset (Wei et al. 2019). Other studies focus on a suppressed convection anomaly as a precursor signal (Matthews 2008; Yong and Mao 2016), in situ moistening by cumulus convection (Ruppert and Johnson 2015; Bellenger et al. 2015), extratropical influences (Ray and Zhang 2010), and equatorial waves (Takasuka et al. 2019).

While the role of horizontal moisture advection in MJO initiation is well documented, there is little work quantifying the role of dry adiabatic lifting. Most studies that analyze the MJO-related moisture budget neglect the contributions from dry adiabatic lifting because of the conventional application of the weak temperature gradient (WTG) approximation (Sobel et al. 2001). In the WTG approximation, dry adiabatic vertical motions are neglected to leading order since they are much smaller than the vertical velocity that balances the diabatic heating associated with deep convection. Hence, moisture budgets that are examined through the conventional application of the WTG approximation neglect the moistening processes from dry adiabatic lifting (Chikira 2014; Wolding et al. 2016; Janiga and Zhang 2016). However, a recent study by Adames et al. (2021) found that the two processes contribute roughly equally to the evolution of water vapor in the tropics. Although vertical moisture advection from convective updrafts is much stronger than that arising from dry adiabatic lifting, it is largely cancelled out by drying from condensation. When the vertical moisture advection and condensation from convection are taken into account together, their net contribution to the evolution of water vapor is similar to that brought about from adiabatic lifting (Adames et al. 2021). Thus, it is possible that adiabatic lifting may play a central role in the convective initiation of the MJO, even when the atmosphere obeys the WTG approximation to leading order.

In this study, we will use a "relaxed" version of the WTG approximation ${ }^{1}$ that does not neglect temperature fluctuations in order to quantify the role that dry adiabatic vertical motions play in the initiation of the MJO. We will show, on the basis of a "relaxed WTG" moisture budget, that vertical moisture advection from dry adiabatic ascent plays an important role in both primary and successive MJO initiation, and its importance is comparable to that of horizontal moisture advection.

\section{Data and methods}

\section{a. Reanalysis and satellite data}

Two datasets are used in this study. The first is the $1.5^{\circ}$ longitude $\times 1.5^{\circ}$ latitude horizontal resolution, four-times-daily

\footnotetext{
${ }^{1}$ The term "relaxed WTG approximation" was introduced by Raymond and Zeng (2005) to refer to a version of the WTG approximation in which the vertical velocities relax temperature anomalies back to a reference value. In the version discussed by Adames et al. (2021), temperature anomalies are instead eliminated by adiabatic vertical velocities. Both versions describe the gravity wave adjustment to WTG balance and can be thought of as the same idea but intended for different applications. The former is intended for numerical modeling while the latter is intended for diagnostic studies.
}

fields from the European Centre for Medium-Range Weather Forecasts ERA-Interim reanalysis (ERA-I herein; Dee et al. 2011) for the 32-yr time period 1979-2010. We make use of the zonal, meridional, and vertical winds $(u, v, \omega)$, specific humidity $(q)$, temperature $(T)$, diabatic heating rate $\left(Q_{1}\right)$, surface and top of the atmosphere radiative fluxes, and surface sensible and latent heat fluxes ( $H$ and $L E$, respectively). The horizontal winds are used to calculate the velocity potential $(\chi)$ following Adames and Wallace (2014). The radiative fluxes are used to calculate the column-integrated radiative heating rate $\left\langle Q_{r}\right\rangle$. We will also calculate fields that are products of individual ERA-I variables. These products are calculated at each time step. Spatial and temporal derivatives are calculated via a centered differences approach. The four-times-daily fields are averaged into daily means. Anomaly fields are obtained by removing the mean climatology at each point in space and time. The anomaly fields are then filtered using a Lanczos filter (Duchon 1979) to retain only variability at the 20-100-day time scale.

In addition to the ERA-I data, we make use of $2.5^{\circ}$ longitude $\times 2.5^{\circ}$ latitude horizontal resolution, daily outgoing longwave radiation (OLR) from NOAA's polar-orbiting satellites (Liebmann and Smith 1996) as an indicator of the extent of the high clouds associated with tropical deep convection.

\section{b. Sounding observations from DYNAMO}

To further analyze the moist process in the MJO initiation and verify the accuracy of the ERA-I data, we used radiosonde measurements taken from the Dynamics of the Madden-Julian Oscillation (DYNAMO). We used data from the northern sounding array (NSA), located mostly north of the equator in the central equatorial Indian Ocean array for a 3-month period from 1 October through 31 December 2011. The NSA is defined by the following sites: Gan Island $\left(0.69^{\circ} \mathrm{N}, 73.51^{\circ} \mathrm{E}\right)$, the $\mathrm{R} / \mathrm{V}$ Revelle $\left(0^{\circ}, 80.5^{\circ} \mathrm{E}\right)$, Colombo $\left(6.91^{\circ} \mathrm{N}, 79.878^{\circ} \mathrm{E}\right)$, and Malé $\left(4.91^{\circ} \mathrm{N}, 73.53^{\circ} \mathrm{E}\right)$. The sounding array dataset has been linearly interpolated in pressure to regular $25-\mathrm{hPa}$ intervals. Details of the sounding data, observing characteristics, and quality control procedures for DYNAMO sounding are documented in Ciesielski et al. (2014). A detailed description of the thermodynamic budget terms used in study is also documented in Johnson et al. (2015). In this study, we used DYNAMO NSA array averages based only on observations (version 3a), available at http://johnson.atmos.colostate.edu/ dynamo/. Radiative heating is also used to calculate the radiative vertical velocity. These data come from the Cloud and the Earth's Radiant Energy System (CERES) product and the Pacific Northwest National Laboratory (PNNL) Combined Retrieval (CombRet) product based on cloud and thermodynamic profile measurements at Gan Island (Feng et al. 2014). The radiative heating data are available from 10 October onward at https://iop.archive.arm.gov/arm-iop/0pidata/feng/.

In section $4 \mathrm{~b}$ we make use of precipitation data from the 3-hourly, $0.25^{\circ} \times 0.25^{\circ}$ horizontal resolution Tropical Rainfall Measuring Mission (TRMM) 3B42 version 7A dataset (Huffman et al. 2007). The TRMM data are area-averaged over the NSA DYNAMO domain in order to create a time 


\section{(a) Primary Events}

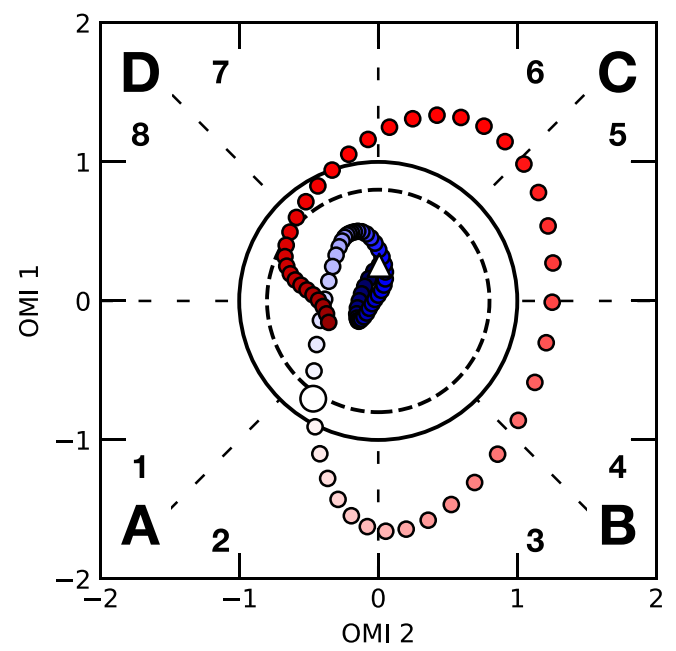

(b) Successive Events

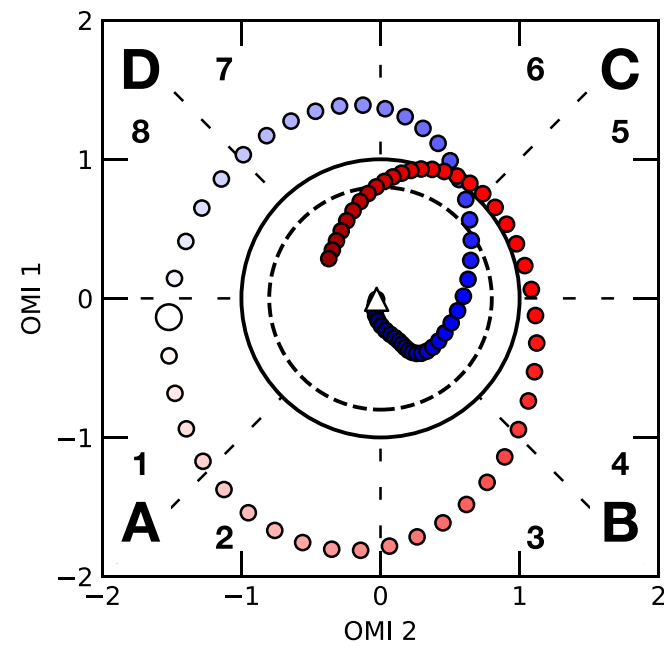

FIG. 1. Composite phase space diagram of the OMI index for days -45 to 45 for (a) primary and (b) successive initiation events. The solid black circle represents an amplitude of 1.0. The dashed circle represents an amplitude of 0.8 , the threshold necessary for events to not be categorized as $\mathrm{N}$ (for no MJO activity). The white triangle marker denotes lag day -45 and the larger circle marker denotes lag day 0 . The shading of the circles changes with increasing time, with darker blues indicating negative lags and reds indicating positive lags. The four quadrants and their corresponding MJO phases are shown in the corners of each panel.

series of rainfall that can be compared to the array-averaged sounding data.

\section{c. Identification and compositing of MJO initiation events}

MJO activity is usually described via the use of an orthogonal pair of time series that describe the evolution of the MJO as it propagates around the equatorial belt. We will make use of the all-season OLR MJO Index (OMI; Kiladis et al. 2014) as our measure of MJO activity. The index is based solely on OLR data and thus more suitable to use to analyze the initiation of the MJO's convective signature over the Indian Ocean.

Our method for identifying MJO initiation events follows those of Matthews (2008), except MJO phases are defined using the OMI index. The standard MJO phase space is divided into four quadrants and assigned the following letters. Quadrant A includes OMI phases 1 and 2, quadrant $B$ includes phases 3 and 4, quadrant $C$ includes phases 5 and 6 , and quadrant $\mathrm{D}$ includes phases 7 and 8 (Fig. 1). For the MJO to be considered active in these quadrants the amplitude of the OMI index, defined as $\sqrt{\mathrm{OMI}^{2}+\mathrm{OMI}^{2}}$, must be greater than 0.8. If the $\mathrm{MJO}$ was inactive during this period, the letter $\mathrm{N}$ is assigned instead. Our threshold for MJO activity is stricter than the Matthews (2008) threshold of 0.4. However, our threshold is lower than the traditional threshold of an amplitude of unity. Our choice of an amplitude of 0.8 is a compromise between the Matthews (2008) threshold, which captures a larger amount of initiation events, and the standard definition of MJO activity, which would capture less but more robust activity.

A subset of MJO initiation events are defined as "primary." These are initiation events that occur in the absence of preceding MJO activity. Following the aforementioned lettering convention, primary events evolve in the MJO phase space following a letter pattern of NABCD. Successive events are defined as initiation events that occur while the OMI maintains an amplitude of 0.8 or greater, and hence evolve in the MJO phase space following the letter pattern DABCD. In this study we define the first day of MJO initiation as the first day that is categorized as A following $\mathrm{D}$ and $\mathrm{N}$ for successive and primary events, respectively. Following this method, we identify 25 primary and 52 successive MJO initiation events.

Many of the plots shown in this study are lag composites of the 25 primary and 52 successive initiation events. In these composites, lag day 0 roughly corresponds to the day in which the moisture tendency $\left(\partial_{t} q\right)$ is a maximum. We define MJO initiation as the period in which the moisture anomalies are positive and $\partial_{t} q>0$, a period of roughly 10 days that begins near lag day 0 . Since we are interested in both the processes that lead up to initiation as well as those that amplify the MJO during initiation, we will analyze a 31-day period that is centered at lag-day 0 . While this period may seem long, it provides a clearer picture of how the MJO evolves before, during, and after initiation. Our results are not sensitive to the choice of initiation period as long as it is centered on lag day 0 .

Statistical significance of the composited fields is obtained from a two-tailed $t$ test under the null hypothesis that the composited fields are uncorrelated with the evolution of the OMI during MJO initiation. The contour and shading in all the figures in this study are statistically significant at the $95 \%$ confidence interval.

\section{Moisture budget under the relaxed WTG approximation}

The equations that describe the conservation of thermodynamic energy and specific humidity in isobaric coordinates can be respectively written as 


$$
\begin{gathered}
\frac{\partial C_{p} T}{\partial t}+\mathbf{v} \cdot \nabla C_{p} T+\omega \frac{\partial s}{\partial p}=Q_{1}, \\
\frac{\partial L q}{\partial t}=-\mathbf{v} \cdot \nabla L q-\omega \frac{\partial L q}{\partial p}-Q_{2},
\end{gathered}
$$

where $C_{p}$ is the specific heat of dry air, $T$ is the temperature, $L$ is the latent heat of vaporization, $q$ is the specific humidity, $\mathbf{v}$ is the horizontal vector wind field, $\omega$ is the vertical velocity, $s=C_{p} T+\Phi$ is the dry static energy, and $Q_{1}$ and $Q_{2}$ are the apparent heat source and moisture sink, respectively defined as in Yanai et al. (1973). As shown in appendix A, Eq. (1a) is a variant of the isobaric thermodynamic energy equation. It can be turned into a dry static energy equation if horizontal and temporal fluctuations in geopotential are assumed small.

As discussed by Adames et al. (2021) and Adames and Maloney (2021), vertical moisture advection and $Q_{2}$ are the largest terms in Eq. (1b) and tend to cancel one another. This cancellation is a result of convective processes, which dominate both the vertical moisture advection and $Q_{2}$. However, other processes also contribute vertical moisture advection that may contribute nonnegligibly to the evolution of moisture. As a result, it is more useful to recast Eq. (1b) in a form where the diabatic processes are separated from the other processes that contribute to vertical moisture advection. This rewriting of the moisture equation can be done by following Adames et al. (2021) and Mapes (1997), who decomposed the vertical velocity into a diabatic $\left(\omega_{Q}\right)$ and a dry adiabatic $\left(\omega_{a}\right)$ component:

$$
\omega=\omega_{Q}+\omega_{a}
$$

where the diabatic component satisfies WTG balance exactly:

$$
\omega_{Q} \frac{\partial s}{\partial p} \equiv Q_{1}
$$

While this definition of $\omega_{Q}$ is exact, it is worth noting that in defining it we are also assuming that there is a diabatically driven horizontal flow that satisfies mass continuity with $\omega_{Q}$. This horizontal flow can impact the thermodynamics of the $\mathrm{MJO}$ - and hence the temporal tendency of $Q_{1}$-by horizontally advecting moisture and temperature, and by forcing isentropic lifting. However, it does not, by definition, play a role in Eq. (3). In this study, we will focus on examining the roles of $\omega_{Q}$ and $\omega_{a}$ in MJO initiation. The potential role of the diabatically driven horizontal flow on the dynamics of the MJO will be examined in the future.

The adiabatic component is much smaller than the diabatic component (see Fig. 5 in Adames et al. 2021) and is driven by temperature tendencies that result from gravity wave activity as well as horizontal temperature advection:

$$
\frac{\partial C_{p} T}{\partial t}+\mathbf{v} \cdot \nabla C_{p} T+\omega_{a} \frac{\partial s}{\partial p}=0 .
$$

The dry adiabatic vertical velocity can be obtained as a residual between the total vertical velocity and the diabatically driven component: $\omega_{a}=\omega-\omega_{Q}$. Alternatively, it can be estimated directly as proportional to the sum of the temperature tendency and the horizontal temperature advection term (Adames et al. 2021). We choose the former method because the calculation of both the temperature tendency and the horizontal advection require estimating derivatives, which introduces additional uncertainty to the estimation of $\omega_{a}$.

It is worth noting that the definitions of $\omega_{Q}$ and $\omega_{a}$ mirror those of the geostrophic and ageostrophic wind that are used in quasigeostrophic theory. In this case, $\omega_{Q}$ describes the component of $\omega$ that is in exact WTG balance, akin to how the geostrophic wind describes the component of the horizontal wind that is in exact geostrophic balance. In a similar fashion, $\omega_{a}$ depicts the small departures from WTG balance that determine the evolution of temperature, similar to how the ageostrophic wind describes the small departures from geostrophic balance that determine the evolution of the horizontal flow in quasigeostrophic theory.

Following Yanai et al. (1973), we can show that the difference between $Q_{1}$ and $Q_{2}$ describes the sum of radiative heating and the eddy flux convergence of eddy moist static energy (MSE):

$$
Q_{1}-Q_{2}=Q_{r}-\frac{\partial \overline{\omega^{\prime} m^{\prime}}}{\partial p}
$$

where $m=C_{p} T+\Phi+L q$ is the MSE. By separating the vertical velocity into its adiabatic and diabatic components and applying Eq. (5), we can column integrate Eq. (1b) and write it as

$$
\begin{aligned}
\frac{\partial\langle L q\rangle}{\partial t}= & -\langle\mathbf{v} \cdot \nabla L q\rangle-\left\langle\omega_{a} \frac{\partial L q}{\partial p}\right\rangle-\left\langle\omega_{Q} \frac{\partial m}{\partial p}\right\rangle \\
& +\left\langle Q_{r}\right\rangle+L E+H,
\end{aligned}
$$

where the angle brackets denote a mass-weighted vertical integral from the tropopause level $\left(p_{t}=100 \mathrm{hPa}\right)$ to the surface $\left(p_{s}=1000 \mathrm{hPa}\right)$, that is,

$$
\langle q\rangle=\frac{1}{g} \int_{p_{t}}^{p_{s}} q d p .
$$

The terms on the right-hand side of Eq. (6) are the columnintegrated horizontal moisture advection, vertical moisture advection by adiabatic vertical motions, vertical MSE advection by diabatic vertical motions, column radiative heating, and the surface latent and sensible heat fluxes, respectively. The vertical advection of MSE by $\omega_{Q}$ is the difference between vertical moisture advection by $\omega_{Q}$ and the apparent heat source

$$
-\left\langle\omega_{Q} \frac{\partial m}{\partial p}\right\rangle=-\left\langle\omega_{Q} \frac{\partial L q}{\partial p}\right\rangle-\left\langle Q_{1}\right\rangle
$$

where Eq. (3) is used to write $Q_{1}$ as a vertical dry static energy (DSE) advection.

Equation (6) is more useful than Eq. (1b) since diabatic processes are condensed into a single term instead of being contained within two. The other contributions to vertical moisture advection in Eq. (1b) are the radiative heating term and the vertical moisture advection by $\omega_{a}$. These were implicit in Eq. (1b) but are explicit in Eq. (6). Adames et al. (2021) showed that the processes in Eq. (6) are of the same order of magnitude, and hence can contribute equally to the evolution of moisture.

\section{Results}

\section{a. Composite primary and successive MJO initiation}

The evolution of the composited OMI index is shown for reference in Fig. 1. In primary events, the amplitude of the 
(a) Primary Events

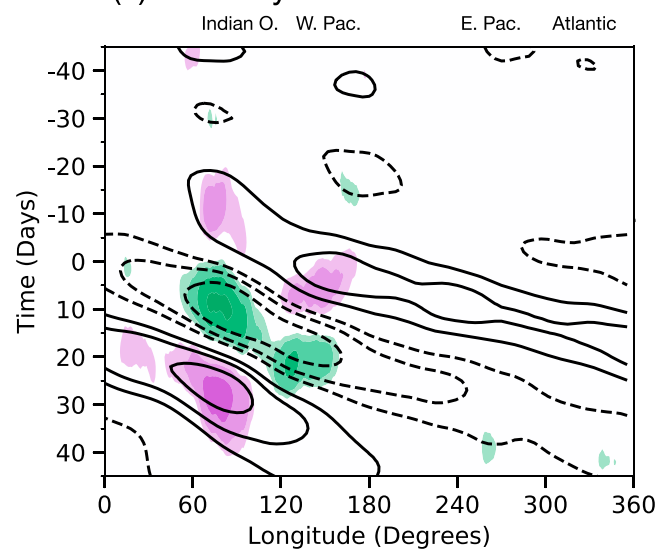

(b) Successive Events

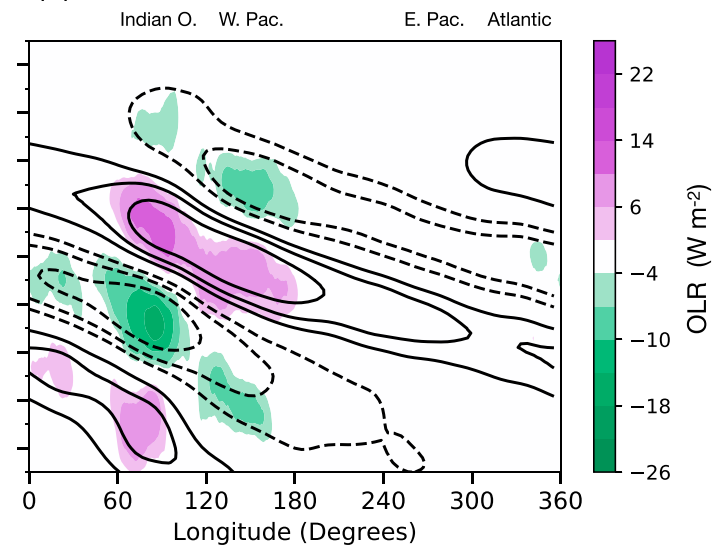

FIG. 2. Hovmöller diagram of 20-100-day filtered anomalous outgoing longwave radiation (OLR) (shaded) and 150 -hPa velocity potential (contoured) averaged over the $10^{\circ} \mathrm{N}-10^{\circ} \mathrm{S}$ latitude belt for (a) the lag composite of 25 primary MJO initiation events and (b) the composite of 52 successive initiation events. The ordinate shows the lag days from the time of initiation, with negative lags indicating days prior to the start of MJO initiation and positive lags indicating days after initiation. The contour interval is $10^{5} \mathrm{~m}^{2} \mathrm{~s}^{-2}$.

OMI index reaches a value of 0.8 at lag day 0 , and no MJO activity is seen prior to this day. In contrast, during successive initiation events the amplitude of the OMI index exceeds a value of unity for $\sim 18$ days prior to lag day 0 . Both primary and successive initiation increase in amplitude after lag day 0 , both reaching a maximum amplitude near lag day 8 . Slow decay is observed thereafter, with the primary initiation event terminating near MJO phase 7 and the successive event decaying near phase 6 . The overall evolution of the two types of initiation events closely follows that described by Matthews (2008). Of course, individual MJO cases within each composite may behave much differently than the mean (not shown).

Time-longitude (Hovmöller) diagrams of the primary and successive MJO initiation events are shown in Figs. $2 \mathrm{a}$ and $2 \mathrm{~b}$, respectively. During primary events, a weak positive OLR anomaly is seen collocated with a positive $150-\mathrm{hPa} \chi$ anomaly over the Indian Ocean at lag day -12 . The OLR signal does not show any clear eastward propagation and decays by lag day -5 while the $\chi$ anomalies exhibit slow eastward propagation. Another positive OLR anomaly is seen near lag day 0 over the western Pacific $\left(150^{\circ} \mathrm{E}-180^{\circ}\right)$, in association with the eastward propagation of the $150-\mathrm{hPa} \chi$ anomalies. Near this time, a negative $150-\mathrm{hPa} \chi$ anomaly is observed propagating into the Indian Ocean from Africa, with negative OLR anomalies appearing at the time the $\chi$ anomalies reach the Indian Ocean. There is no statistically significant evidence that these $\chi$ anomalies come from a previous MJO event. Instead, the statistically significant signal initiates over South America near $300^{\circ}\left(120^{\circ} \mathrm{W}\right)$. Sakaeda and Roundy (2016) showed that the upper-tropospheric Kelvin wave circulation associated with primary MJO initiation tends to develop in this region.

As the positive OLR anomalies decay, substantial amplification of the negative OLR anomalies occurs over the Indian Ocean, reaching a maximum amplitude near lag day 5. Unlike the positive OLR anomalies that precede it, the negative OLR anomalies exhibit a coherent pattern of eastward propagation up to lag day 25, where they decay near the date line.

In contrast to the primary initiation events, the successive events shown in Fig. $2 b$ show a coherent propagating signal that can be traced back to lag day -35 . A succession of eastward-propagating positive and negative OLR anomalies can be seen from lag day -35 , and they are organized into a pattern that is reminiscent of a wave train. These results are similar to those shown in Matthews (2008) but are shifted by about 5 days, largely a result of our choosing a different MJO index [see Table 2 in Kiladis et al. (2014) for more details].

A similar distinction between primary and successive events can be made by examining column-averaged $\omega_{Q}$ and $\omega_{a}$. The evolution of OLR and $\omega_{Q}$ is shown for primary and successive events in Figs. $3 \mathrm{a}$ and $3 \mathrm{~b}$ respectively. It is clear that diabatic vertical motions closely follow the OLR signal. The largest velocities are associated with deep convection and are largely confined to the warm pool. In both cases, $\omega_{Q}$ seems to originate over eastern Africa. However, the signal in this region is more coherent and spatially coincides with a weak OLR signal in the successive events. In contrast, $\omega_{a}$ closely follows the progression of the $\chi$ anomalies (Figs. 3c,d) around the world instead of appearing only where convection was active. For successive events (Fig. 3d) we observe a signal in $\omega_{a}$ associated with the circumnavigating MJO signal $(\chi)$ that is seen propagating toward the Indian Ocean prior to MJO initiation. This signal can be traced back to the first MJO event in the sequence near lag day -35 and has a magnitude as large as $-0.045 \mathrm{~Pa} \mathrm{~s}^{-1}$. In contrast, a significant $\omega_{a}$ is not apparent until lag day 0 during primary initiation events. The noisy appearance of the $\omega_{a}$ signal near $30^{\circ}$ and $300^{\circ} \mathrm{E}$ are likely the result of the Ethiopian highlands and the Andes, respectively.

The results of Figs. 2 and 3 show a contrasting evolution of the OLR, $\omega_{Q}$, and $\omega_{a}$ fields in the primary and successive MJO events. To understand the evolution of convection during MJO initiation, we analyze the terms that lead to the evolution of 
(a) Primary Events

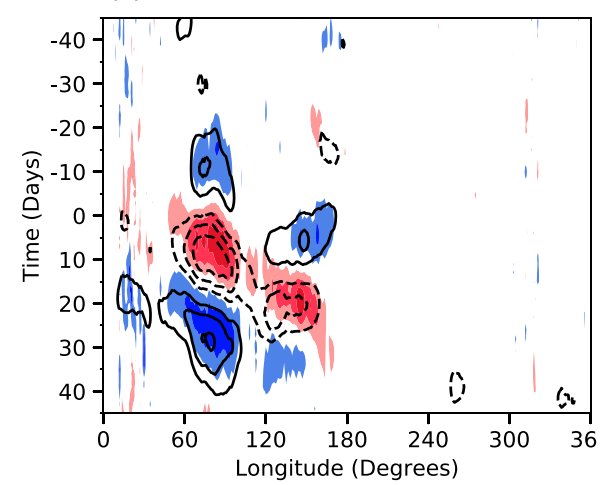

(c)

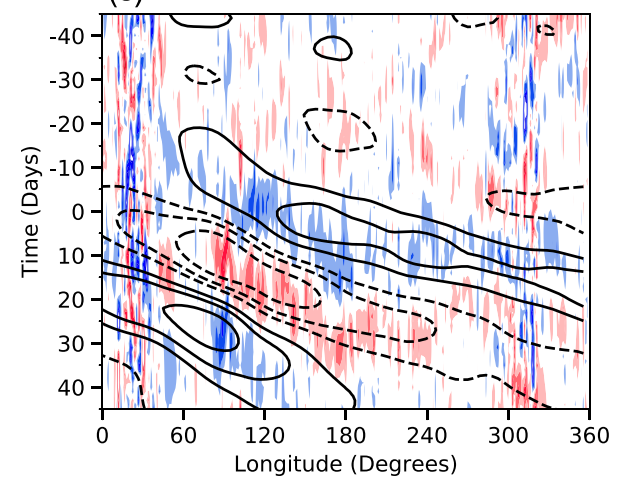

(b) Successive Events

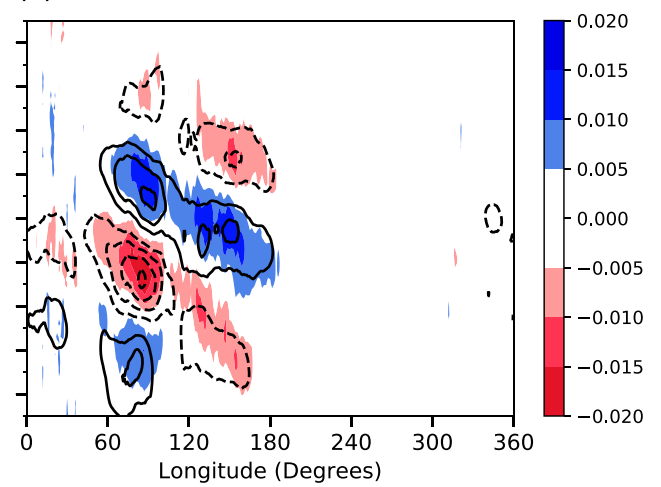

(d)

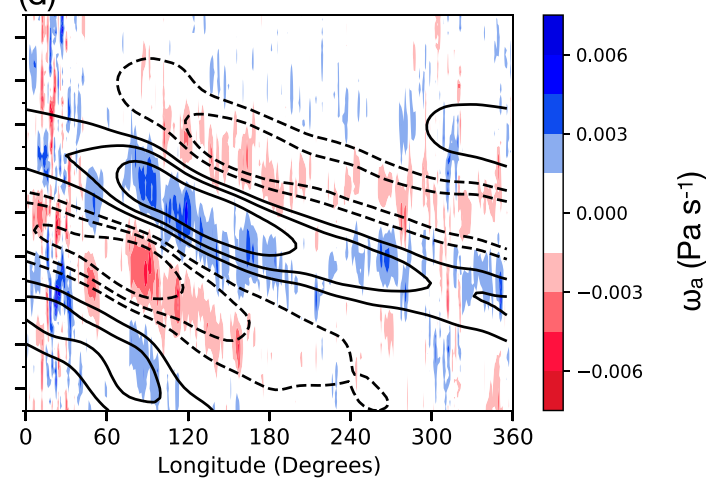

FIG. 3. As in Fig. 2, but showing (top) 20-100-day filtered anomalous column average $\omega_{Q}$ (shaded) and OLR (contours) for (a) primary and (b) successive initiation events. (bottom) 20-100-day filtered anomalous columnaveraged $\omega_{a}$ (shaded) and 150-hPa velocity potential ( $\chi$, contoured) for (a) primary and (b) successive initiation events. The contour interval is $4 \mathrm{~W} \mathrm{~m}^{-2}$ in the top panels and $10^{5} \mathrm{~m}^{2} \mathrm{~s}^{-1}$ in the bottom panels.

moisture in Eq. (6). For comparison, the column-integrated moisture anomalies are also shown (Fig. 4), which feature an evolution pattern that is reminiscent of the OLR anomalies in Fig. 2. The top panel of Fig. 4a shows that, during the initiation of primary events, moistening is seen over the Indian Ocean starting around lag day -5 . The moisture tendency propagates eastward, showing a structure in the Hovmöller diagram that is reminiscent of the $\langle q\rangle$ anomalies, but shifted by about -10 lag days. For primary events, the moisture tendency prior to MJO onset does not extend to the west of the Indian Ocean, suggesting a weaker or nonexistent circumnavigating signal.

Figures $4 \mathrm{~b}-\mathrm{d}$ show the terms of the right-hand side of Eq. (6) that dominate the evolution of moisture during primary MJO initiation. These are horizontal moisture advection $(-\langle\mathbf{v} \cdot \nabla L q\rangle)$, vertical advection of moisture by dry adiabatic vertical motions $\left(-\left\langle\omega_{a} \partial_{p} L q\right\rangle\right)$, and vertical MSE advection by diabatic vertical motions $\left(-\left\langle\omega_{Q} \partial_{p} m\right\rangle\right)$. Horizontal moisture advection (Fig. $\left.4 \mathrm{~b}\right)$ exhibits a similar pattern to the moisture tendency, albeit noisier. In contrast, $-\left\langle\omega_{a} \partial_{p} L q\right\rangle$ (Fig. $4 \mathrm{c}$ ) and $-\left\langle\omega_{Q} \partial_{p} m\right\rangle$ exhibit a similar amplitude to large-scale horizontal advection. However, the two processes are more in phase with the column moisture anomalies rather than the moisture tendency, suggesting that these processes are related to MJO maintenance. They also exhibit opposite polarities and therefore tend to cancel one another, except away from the warm pool where $-\left\langle\omega_{a} \partial_{p} L q\right\rangle$ is dominant. That $-\left\langle\omega_{Q} \partial_{p} m\right\rangle$ acts to dry the column during active MJO events is suggestive of stratiform convection (Inoue and Back 2015; Inoue et al. 2020).

In contrast to primary initiation events, the moisture tendency associated with the initiation of successive events (Fig. 4e, bottom) exhibits a coherent pattern of propagation as early as lag day -20 at $90^{\circ} \mathrm{E}$, where an eastwardpropagating drying tendency is observed. The drying is followed by eastward-propagating dry anomalies, which are then followed by moistening near lag day -10 . The moistening leading to successive MJO initiation occurs at the same lags that moistening occurs for primary MJO initiation. The relative amplitude of the processes that contribute to the moisture tendency during successive initiation are comparable to those occurring during primary initiation. However, in contrast to primary events, the moistening for successive events at lag day -5 extends all the way to eastern Africa $\left(\sim 0^{\circ}\right.$ longitude). Moistening by $-\left\langle\omega_{a} \partial_{p} L q\right\rangle$ exhibits the largest amplitude over this region.

To more clearly quantify the evolution of the moist processes leading to MJO initiation, we average the moist processes in Fig. 4 over the Indian Ocean $\left(10^{\circ} \mathrm{N}-10^{\circ} \mathrm{S}, 60^{\circ}-100^{\circ} \mathrm{E}\right)$ and show them as line plots in Fig. 5. For primary initiation events, horizontal moisture advection (green) peaks at lag day -5 . Moistening by $-\left\langle\omega_{a} \partial_{p} L q\right\rangle$ (blue) is a maximum near lag day 7 , about the same time the $\langle q\rangle$ anomalies (black) reach 
Primary Events
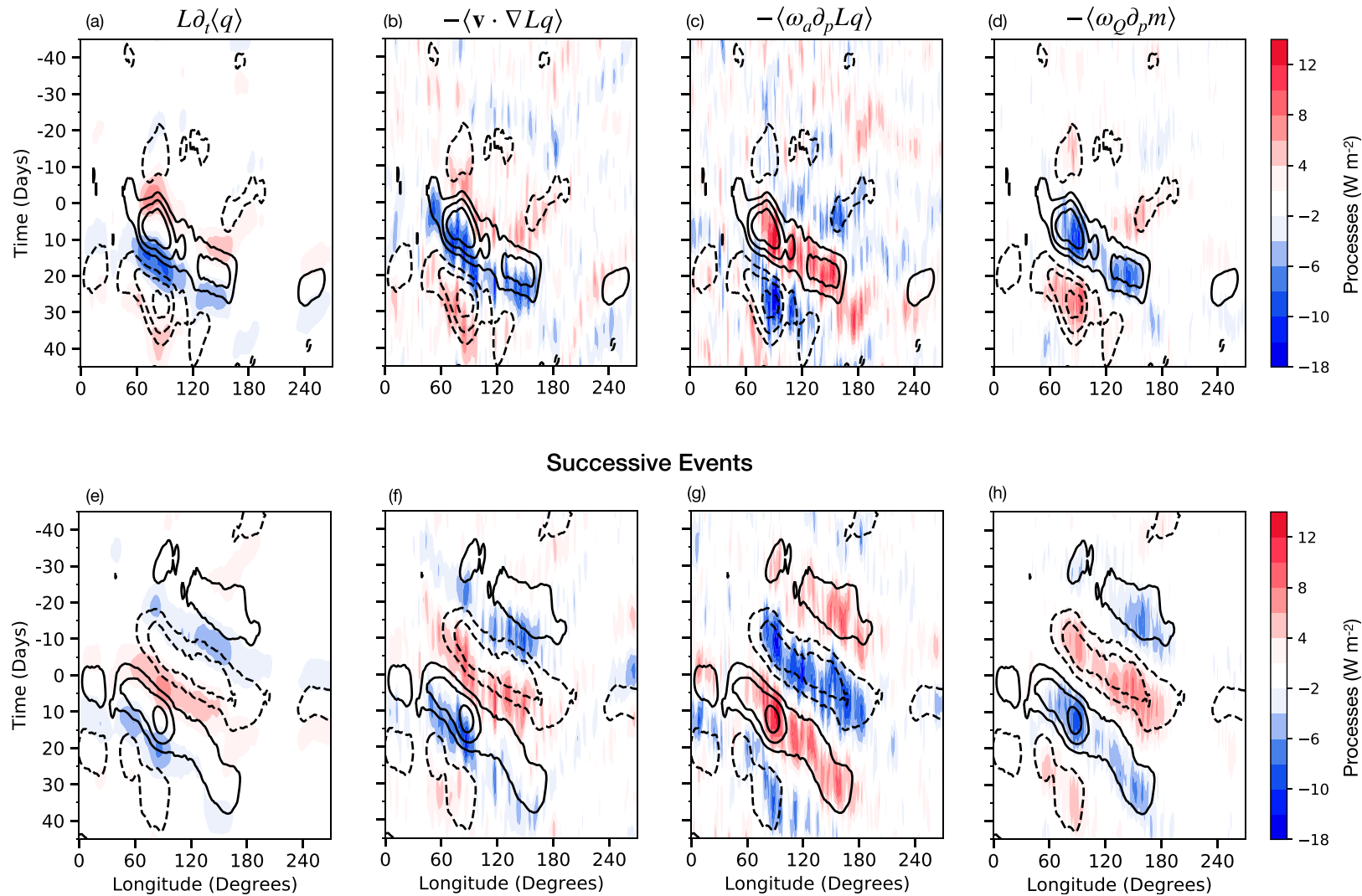

FIG. 4. Hovmöller diagram of filtered (20-100 days) column-integrated thermodynamic term anomalies (shading) and $\langle q\rangle$ anomalies (contoured) averaged over the $10^{\circ} \mathrm{N}-10^{\circ} \mathrm{S}$ latitude belt for both primary and successive events. (a) Moisture tendency term, (b) $-\langle\mathbf{v} \cdot \nabla L q\rangle$, (c) $-\left\langle\omega_{a} \partial_{p} L q\right\rangle$, and (d) $-\left\langle\omega_{Q} \partial_{p} m\right\rangle$. The contour interval for $\langle q\rangle$ is $0.5 \mathrm{~mm}$.

their maximum amplitude. Radiative heating (orange) slightly lags $-\left\langle\omega_{a} \partial_{p} L q\right\rangle$, peaking near lag day 9. Both $-\left\langle\omega_{a} \partial_{p} L q\right\rangle$ and radiative heating are related to $\mathrm{MJO}$ maintenance, and largely counteract the drying from $-\left\langle\omega_{Q} \partial_{p} m\right\rangle$ (red). The offset between the terms is depicted in Fig. 5 b by the purple line, which illustrates the sum of all terms on the right-hand side of Eq. (6).

Successive MJO initiation events exhibit a similar evolution in horizontal moisture advection albeit with a larger magnitude, which also peaks at lag day -5 . Moistening by $-\left\langle\omega_{Q} \partial_{p} m\right\rangle$ is also seen from lag day -15 to lag day 0 , in association with the preceding MJO suppressed phase. As in primary initiation events, $-\left\langle\omega_{a} \partial_{p} L q\right\rangle,-\left\langle\omega_{Q} \partial_{p} m\right\rangle$, and $\left\langle Q_{r}\right\rangle$ all reach their maximum amplitude near the time when the $\langle q\rangle$ anomalies reach their maximum amplitude. However, there are some small shifts in the time these fields reach a maximum amplitude when compared to primary initiation events. For example, $\langle q\rangle$ reaches a maximum amplitude near lag day 10, compared to lag day 7 for primary events. Relative to the maximum in $\langle q\rangle$, the maximum in $-\left\langle\omega_{a} \partial_{p} L q\right\rangle$ occurs at an earlier time in successive initiation events, and its amplitude is $\sim 50 \%$ larger than in primary initiation events. Conversely, $\left\langle Q_{r}\right\rangle$ and $-\left\langle\omega_{Q} \partial_{p} m\right\rangle$ shift in such a way that their phasing relative to $\langle q\rangle$ in successive initiation events is similar to that of primary events. The amplitude of these two processes is also similar for both types of MJO initiation.
When all the terms on the right-hand side in Eq. (6) are added together (purple line in Fig. 5b), we find that it is not equal to the moisture tendency. A residual in the moisture budget exists that exhibits an amplitude and structure similar to that found by Kim et al. (2014), being largely in phase with the horizontal moisture advection albeit with a slightly smaller amplitude. The signal is likely not related to the large-scale moisture advection. It is likely due to the analysis increments that exist in reanalysis data (Mapes and Bacmeister 2012; Ren et al. 2021), which are related to an improper representation of convection and its interaction with moisture and radiation (Kim et al. 2014b; Yokoi 2015).

Following Andersen and Kuang (2012), Adames (2017) and others, we can estimate the contribution of different processes to the initiation of the MJO by projecting the moist processes to the moisture anomalies and the moisture tendency, following the formula

$$
\operatorname{Proj}(X,\langle L q\rangle)=\frac{\|X \cdot\langle L q\rangle\|}{\|\langle L q\rangle \cdot\langle L q\rangle\|}
$$

where $\|\cdot\|$ implies a sum over the Indian Ocean domain $\left(10^{\circ} \mathrm{N}-10^{\circ} \mathrm{S}, 60^{\circ}-100^{\circ}\right)$, and from lag days -15 to 15 , and $X$ corresponds to any of the processes described in Eq. (6). In 

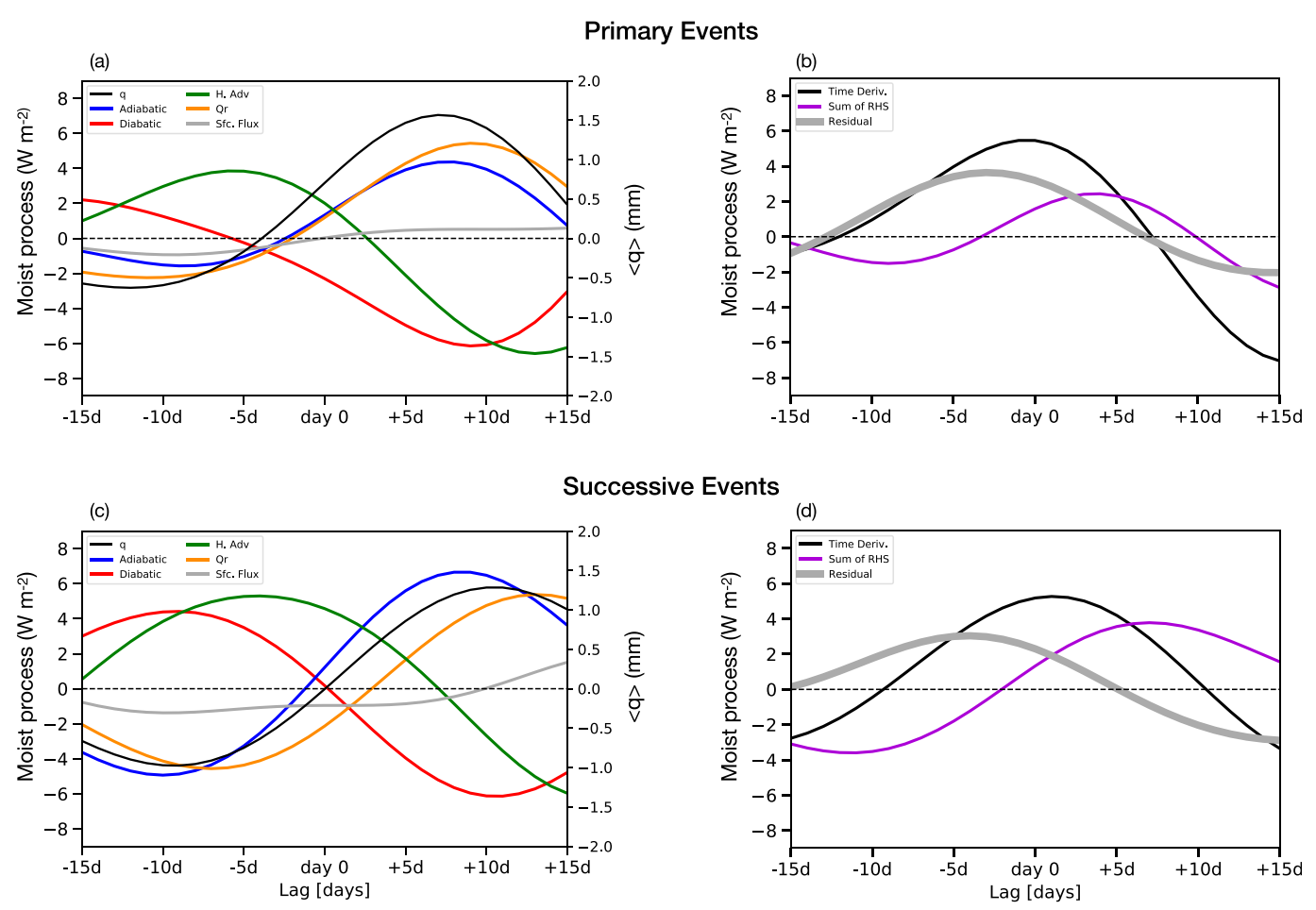

FIG. 5. Lag composites of the column integrated moisture budget filtered for the MJO (20-100 days) and averaged over the Indian Ocean $\left(10^{\circ} \mathrm{N}-10^{\circ} \mathrm{S}, 60^{\circ}-100^{\circ} \mathrm{E}\right)$ for (top) primary and (bottom) successive events. (a), (c) Temporal evolution of $-\left\langle\omega_{a} \partial_{p} L q\right\rangle$ (blue), $-\left\langle\omega_{Q} \partial_{p} m\right\rangle$ (red), horizontal moisture advection (green), radiative heating $\left\langle Q_{r}\right\rangle$ (orange), surface fluxes (gray), and column-integrated specific humidity (black). (b),(d) Temporal evolution of the moisture tendency (black), the sum of all the right-hand-side terms in Eq. (6) (purple), and the budget residual (gray).

previous studies, these projections would describe the contribution of moist processes to $\mathrm{MJO}$ maintenance $[\operatorname{Proj}(X$, $\langle L q\rangle)]$ and propagation $\left[\operatorname{Proj}\left(X, \partial_{t}\langle L q\rangle\right)\right]$. Since we are focused on MJO initiation in this study, $\operatorname{Proj}\left(X, \partial_{t}\langle L q\rangle\right)$ can be thought to describe the relative contribution of different processes to the moistening that contribute to convective onset while $[\operatorname{Proj}(X,\langle L q\rangle)]$ describes the relative contribution of different processes to the amplification of the convection. Chronologically speaking, $\left[\operatorname{Proj}\left(X, \partial_{t}\langle L q\rangle\right)\right]$ describes the early stages of MJO initiation, centered on lag day 0 , while $[\operatorname{Proj}(X,\langle L q\rangle)]$ describes the late stages of MJO initiation.

For both primary and successive events, large-scale horizontal moisture advection is the largest contributor to moistening in the Indian Ocean (Figs. 6a,c), consistent with the results of Wolding (2013), Matthews (2008), and Zhao et al. (2013). Moistening by $-\left\langle\omega_{a} \partial_{p} L q\right\rangle$ is the secondlargest contributor. Both horizontal moisture advection and $-\left\langle\omega_{a} \partial_{p} L q\right\rangle$ project more strongly onto the moisture tendency during successive MJO initiation than to primary. A major difference between successive and primary events is the positive role $\left\langle Q_{r}\right\rangle$ plays during primary propagation. This may be attributed to the convective structure of primary versus successive MJO events. Primary initiation events may exhibit a larger preponderance of elevated stratiform clouds than secondary events, which would also be consistent with the larger contribution to drying by $-\left\langle\omega_{Q} \partial_{p} m\right\rangle$. Suppressed surface energy fluxes also act to slow down moistening for successive initiation events.

The moisture anomalies during MJO initiation are maintained by $-\left\langle\omega_{a} \partial_{p} L q\right\rangle$ and $\left\langle Q_{r}\right\rangle$ (Figs. 6b,d). In primary events the two terms are comparable, with $\left\langle Q_{r}\right\rangle$ having a slightly larger contribution. However, in successive events $-\left\langle\omega_{a} \partial_{p} L q\right\rangle$ contributes nearly twice as much to maintenance than $\left\langle Q_{r}\right\rangle$. Horizontal moisture advection and $-\left\langle\omega_{Q} \partial_{p} m\right\rangle$ act to damp the moisture anomalies, with the latter contributing a larger amount. The $-\left\langle\omega_{Q} \partial_{p} m\right\rangle$ is larger for successive events and contributes more to the damping than in primary events. That $\partial_{t}\langle L q\rangle$ projects positively to the moisture anomalies indicates that the moistening terms exceed the drying terms, and the MJO is growing during this stage of its life cycle.

The existence of a substantial residual for both primary and successive propagation suggests that there may be an underestimate of the budget. It slightly leads the moisture tendency and follows a similar pattern to large-scale horizontal advection as seen in Fig. 5. The residual plays a larger role in primary event propagation and is the leading term, possibly indicating a larger role of tropospheric moistening by shallow and congestus clouds, which may not be adequately represented in ERA-I (Kiranmayi and Maloney 2011; Mapes and Bacmeister 2012). For anomaly maintenance the role of the 


\section{Primary Events}

(a) Contribution to <q'> evolution (nondim)

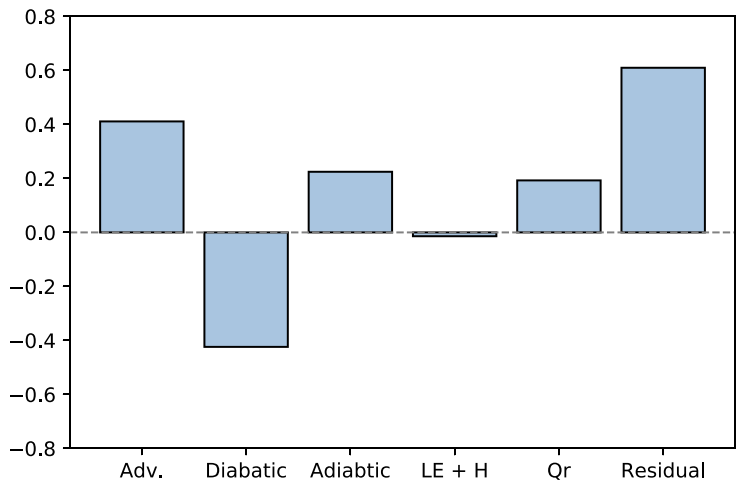

(b) Contribution to $\left\langle q^{\prime}>\right.$ maintenance $\left(\right.$ day $\left.^{-1}\right)$

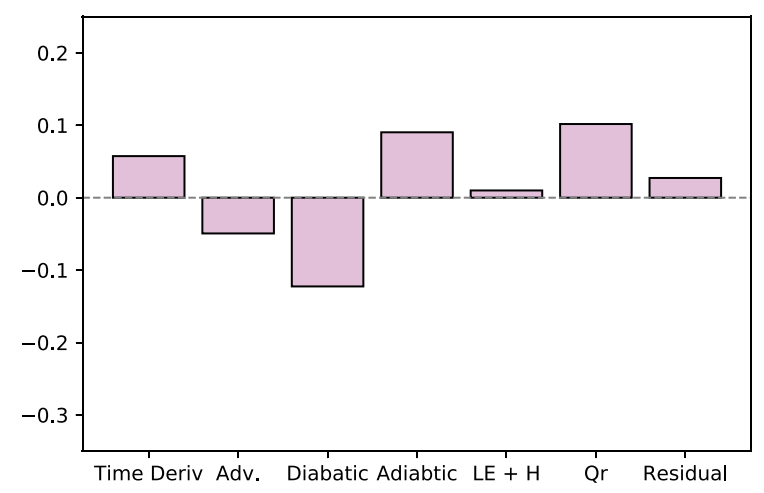

\section{Successive Events}

(c)

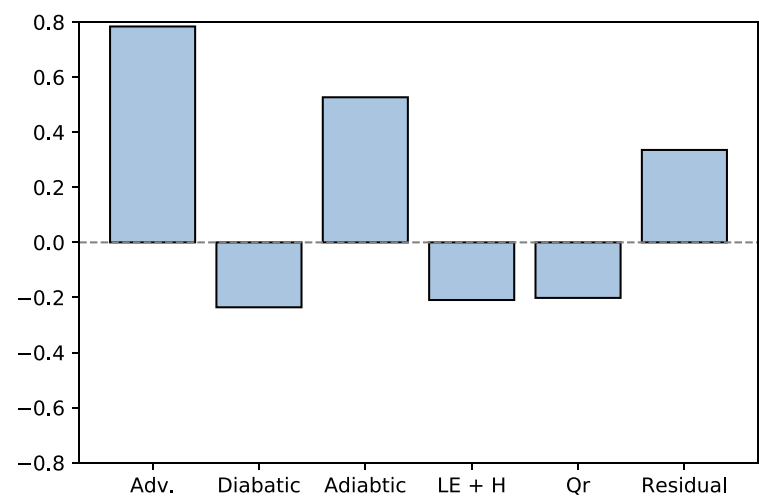

(d)

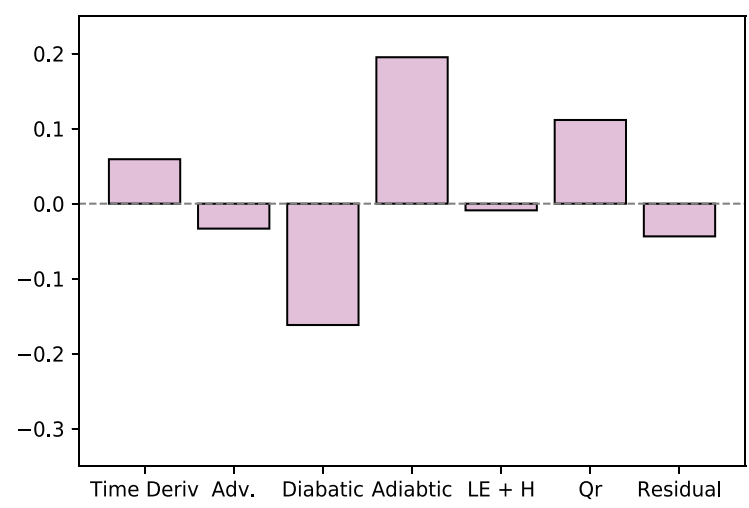

FIG. 6. Fractional contribution of the thermodynamic budget in Eq. (6) of moisture anomaly propagation and maintenance averaged over the Indian Ocean $\left(10^{\circ} \mathrm{N}-10^{\circ} \mathrm{S}, 60^{\circ}-100^{\circ} \mathrm{E}\right)$ for (a),(b) primary events and (c),(d) successive events. The projected terms are (from left to right): $\partial_{t}\langle L q\rangle,-\langle\mathbf{v} \cdot \nabla L q\rangle,-\left\langle\omega_{Q} \partial_{p} m\right\rangle,-\left\langle\omega_{a} \partial_{p} L q\right\rangle,-\left\langle Q_{r}\right\rangle$, and the budget residual.

residual is small but is positive in primary events and negative in successive events.

\section{b. Role of $\omega_{a}$ in MJO initiation during DYNAMO}

Model and numerical errors largely contribute to the residual (Figs. 5 and 6) found in the reanalysis data (Mapes and Bacmeister 2012; Ren et al. 2021). To further examine the validity of Figs. 5 and 6 , we compared these results to those of a sounding-based moisture budget from observations collected during the DYNAMO field campaign, which contain three successive events. Since the observational analysis is limited to three MJO events, Fig. 7 is calculated using linear regression analysis, following the same procedure of previous studies (Mapes et al. 2006; Adames et al. 2021; Mayta et al. 2021). In other words, we regressed moisture budget terms of Eq. (6) against the OMI1 MJO index. This deviates from the methodology found in Matthews (2008) and what was used in the reanalysis composites, although the results are interpreted in the same way as ERA-I composites.

Examination of Fig. 7 reveals that horizontal moisture advection and $-\left\langle\omega_{Q} \partial_{p} m\right\rangle$ moisten the atmosphere prior to MJO initiation.
The moistening is partly offset by anomalous radiative cooling, suppressed surface fluxes, and drying by $-\left\langle\omega_{a} \partial_{p} L q\right\rangle$. As the moisture anomalies increase, these processes reverse polarity. At the time when the $\langle q\rangle$ anomalies attain their maximum amplitude we observe that surface fluxes, radiative heating, and $-\left\langle\omega_{a} \partial_{p} L q\right\rangle$ are positive, suggesting that these processes play a role in MJO maintenance. Moistening from $-\left\langle\omega_{a} \partial_{p} L q\right\rangle$ is roughly of equal importance as surface fluxes in maintaining the convection.

The results from the DYNAMO soundings qualitatively agree with the composites made from ERA-I data, although the processes in the former are nearly an order of magnitude larger than the latter. In both datasets $-\left\langle\omega_{a} \partial_{p} L q\right\rangle$ peaks after the maximum in the moisture tendency occurs and approximately out of phase with $-\left\langle\omega_{Q} \partial_{p} m\right\rangle$. Additionally, in both datasets horizontal moisture advection predominantly contributes to the moisture tendency.

However, there are some notable differences between the DYNAMO and ERA-I datasets. In the DYNAMO data, $\left\langle Q_{r}\right\rangle$ and $-\left\langle\omega_{Q} \partial_{p} m\right\rangle$ are larger in comparison to the moisture tendency than they are in reanalysis. Another significant difference 


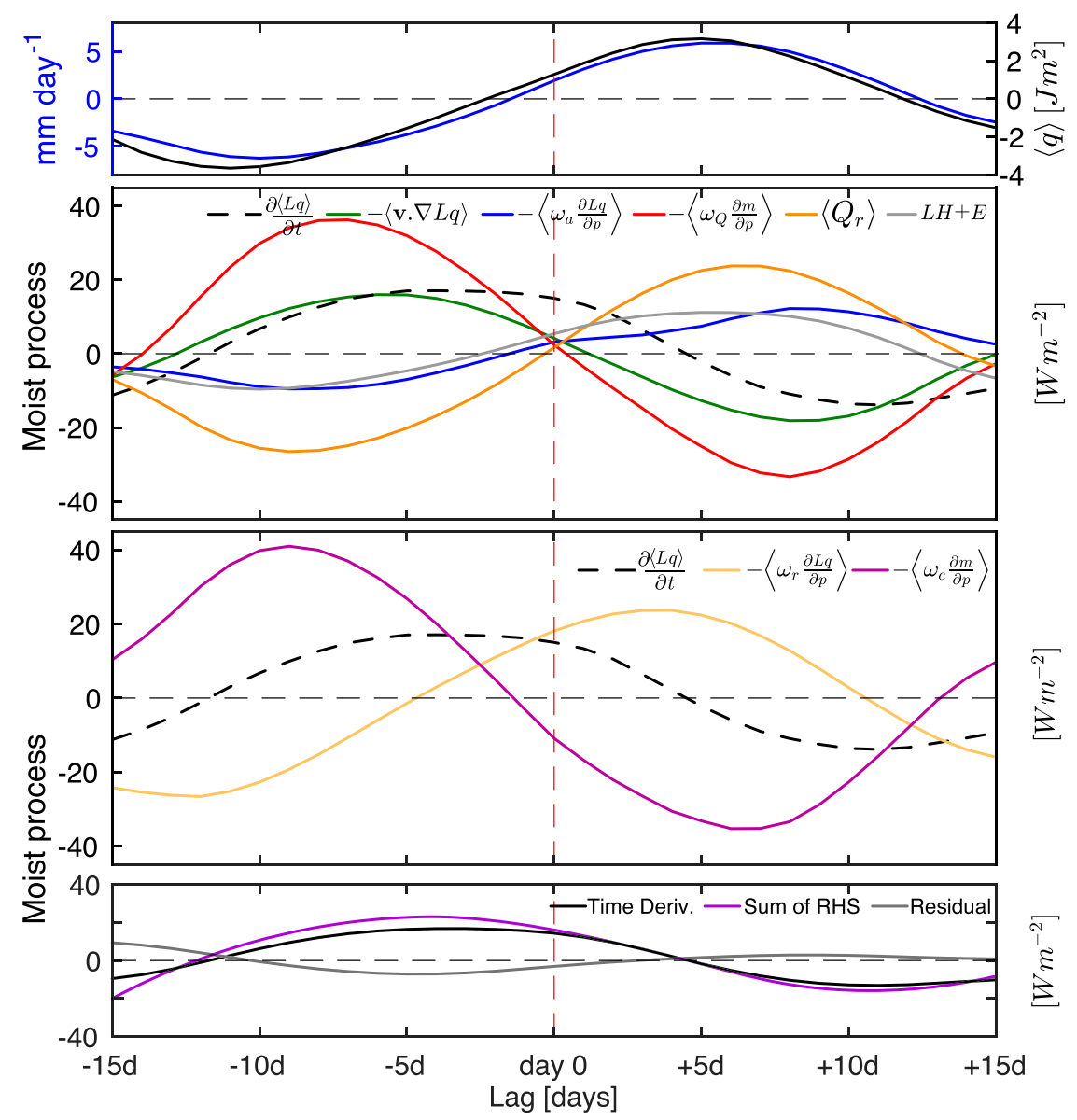

FIG. 7. Lag regression based on the OMI1 time series and moisture budget terms calculated over the DYNAMO northern array. (top) TRMM-3B42 rainfall rate (blue) and column moisture (black). (middle top) Regressed anomalies of moisture budget terms of Eq. (6): $\partial_{t}\langle L q\rangle$ (dashed black), $-\langle\mathbf{v} \cdot \nabla L q\rangle$ (green), $-\left\langle\omega_{a} \partial_{p} L q\right\rangle$ (blue), $-\left\langle\omega_{Q} \partial_{p} m\right\rangle$ (red), $\left\langle Q_{r}\right\rangle$ (orange), and surface turbulent flux $L E+H$ (gray). (middle bottom) Regressed anomalies of moisture budget terms of Eq. (10): $-\left\langle\omega_{c} \partial_{p} m\right\rangle$ (purple) and $-\left\langle\omega_{r} \partial_{p} L q\right\rangle$ (yellow). (bottom) Temporal evolution of the moisture tendency (black), the sum of all the right-hand-side terms in Eq. (6) (purple), and the budget residual (gray).

is the larger role surface fluxes play in the DYNAMO data, which play a negligible role in the reanalysis. In both cases, however, $-\left\langle\omega_{a} \partial_{p} L q\right\rangle$ is roughly the same magnitude as the moisture tendency. In appendix B we show that some of the differences between ERA-I and DYNAMO can be attributed to the domain averaging used in the reanalysis data.

One disadvantage of the use of Eq. (6) is that radiative heating contributes to $-\left\langle\omega_{Q} \partial_{p} m\right\rangle$ due to the large-scale circulations that $\left\langle Q_{r}\right\rangle$ produces in order to satisfy the WTG approximation (Wolding et al. 2016; Adames and Maloney 2021). However, the DYNAMO data allow us to quantify the contributions of radiative and convective heating to $\omega_{Q}$. Following Adames et al. (2021), we rewrite the sum of $\left\langle Q_{r}\right\rangle$ and $-\left\langle\omega_{Q} \partial_{p} m\right\rangle$ as

$$
-\left\langle\omega_{Q} \frac{\partial m}{\partial p}\right\rangle+\left\langle Q_{r}\right\rangle=-\left\langle\omega_{c} \frac{\partial m}{\partial p}\right\rangle-\left\langle\omega_{r} \frac{\partial L q}{\partial p}\right\rangle,
$$

where the terms on the right-hand side are the vertical MSE advection by convective vertical motions $\left(\omega_{c}\right)$ and the vertical moisture advection by radiative vertical motions $\left(\omega_{r}\right)$. It is worth noting that the terms on the right-hand side of Eq. (10) fully separate the contribution of convection and radiation to the column moisture tendency.

The terms on the right-hand side of Eq. (10) are regressed onto the OMI1 time series as was done with the terms of Eq. (6). When we examine the contributions of $-\left\langle\omega_{c} \partial_{p} m\right\rangle$ and $-\left\langle\omega_{r} \partial_{p} L q\right\rangle$ to MJO initiation (third panel of Fig. 7), we find that the former is nearly identical to $-\left\langle\omega_{Q} \partial_{p} m\right\rangle$ and the latter to $\left\langle Q_{r}\right\rangle$, except they are shifted by roughly $2-3$ days. Thus to a first approximation we can interpret $-\left\langle\omega_{Q} \partial_{p} m\right\rangle$ as describing the net moistening by convective motions and $\left\langle Q_{r}\right\rangle$ as describing the moistening of the troposphere by radiative heating. It should be noted that the residual in DYNAMO is close to zero. The maximum difference between the $\partial_{t}\langle L q\rangle$ and the sum of terms in Eq. (6) is observed at 


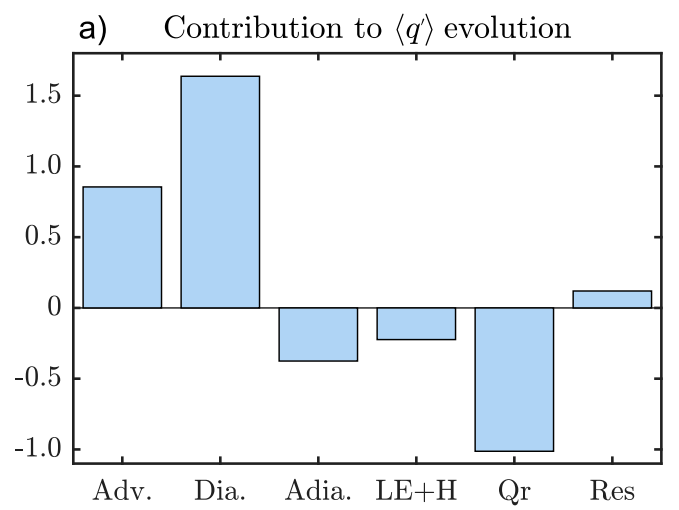

b) Contribution to $\left\langle q^{\prime}\right\rangle$ maintenance

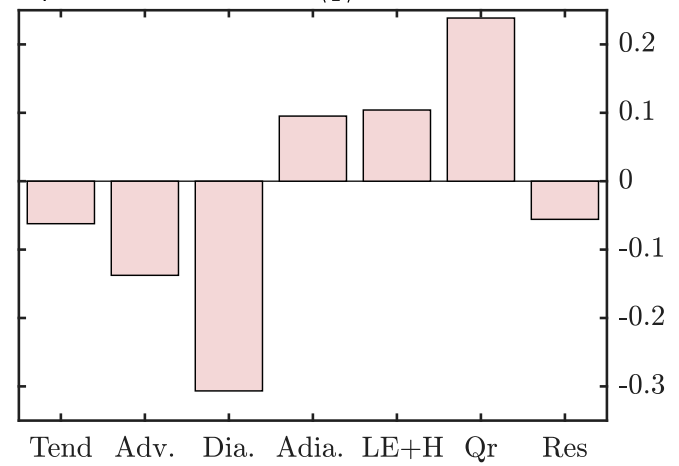

FIG. 8. As in Fig. 6, but for data from the DYNAMO northern sounding array.

lag day -5 , where it is roughly a third of the size of the moisture tendency (bottom panel in Fig. 7). This residual is likely due to numerical errors in calculating the tendency and advection terms.

Last, it is instructive to estimate the contribution of the moist processes calculated from the DYNAMO sounding array to the maintenance and evolution of the moisture anomalies (Fig. 8). When it comes to the processes that lead to the evolution of the moisture anomalies, there are more notable differences between the sounding data and ERA-I. The term $-\left\langle\omega_{a} \partial_{p} L q\right\rangle$ does not significantly contribute to $\partial_{t}\langle L q\rangle$ in the sounding data. Furthermore, $-\left\langle\omega_{Q} \partial_{p} m\right\rangle$ contributes more to the moisture tendency than horizontal moisture advection, which is in stark contrast to ERA-I. This difference cannot be accounted for even if all of the residual in Fig. 6 were allocated to $-\left\langle\omega_{Q} \partial_{p} m\right\rangle$.

When it comes to the processes that maintain the moisture anomalies, it is seen that $-\left\langle\omega_{a} \partial_{p} L q\right\rangle$ contributes roughly the same amount to MJO maintenance as it does in the ERA-I composites. However, the fractional contributions of $-\left\langle\omega_{Q} \partial_{p} m\right\rangle$ and $\left\langle Q_{r}\right\rangle$ are roughly twice as large in the sounding data than in ERA-I. The time derivative also projects weakly negatively to the moisture anomalies. Last, as expected, the residual in the sounding data is much smaller than that found in ERA-I data, and negligible in comparison to the other fields.

\section{Discussion and conclusions}

In the preceding sections, we sought to understand the processes that lead to moistening of the troposphere during primary and successive MJO initiation events over the Indian Ocean. Unlike previous studies, we quantify the role of large-scale dry adiabatic lifting during MJO initiation by employing a "relaxed WTG" moisture budget (Adames et al. 2021). On the basis of a composite analysis similar to that of Matthews (2008) but using the OLR MJO index (OMI) (Kiladis et al. 2014) in ERA-I data, we find that large-scale horizontal advection plays a critical role in the moistening of the troposphere during the days leading up to primary and successive MJO initiation, as suggested by previous studies (Zhao et al. 2013; Wolding 2013; Li et al. 2015). For successive initiation, we interpret this moistening as the result of anomalous easterlies associated with a previous MJO suppressed phase advecting moist air from the Maritime Continent, as previous studies have shown (Zhao et al. 2013; Nasuno et al. 2015). Suppressed convection also exists prior to primary MJO initiation, and it is possible that it aids the onset of the active MJO by moistening the troposphere through horizontal moisture advection. It is also possible that nonlinear moisture advection plays a significant role in both primary and successive initiation events, as suggested by Nasuno et al. (2015) and Wei et al. (2019).

We also find that vertical moisture advection by adiabatic lifting is of leading-order importance for the initiation of both primary and successive events (Fig. 6). Large-scale horizontal moisture advection and dry adiabatic lifting are of comparable magnitude but large-scale horizontal advection peaks prior to initiation while adiabatic motions become more important as convection is increasing over the Indian Ocean, as shown in Fig. 5. Because dry adiabatic lifting peaks as the convection is increasing over the Indian Ocean, we also find that this process plays a significant role in MJO maintenance. Its role in maintenance is comparable to that of radiative heating in primary initiation events, while it is larger for successive events. While it is well known that radiative heating plays an important role in MJO maintenance (Andersen and Kuang 2012; Kim et al. 2014; Sobel et al. 2014), the importance of dry adiabatic lifting in MJO maintenance has not been previously documented.

By synthesizing Figs. 2-8, we can obtain a clearer picture of the sequence of events that lead to MJO initiation over the Indian Ocean, as shown schematically in Fig. 9. In successive events, a circumnavigating signal is seen in the $\chi$ anomalies that are traced back to a previous active MJO event that was propagating over the warm pool during lag days -25 to -10 . The circumnavigating signal returns to the Indian Ocean near lag day 5 , coinciding with the increase in dry adiabatic lifting over this region. This lifting reinforces the moistening tendency over the Indian Ocean, which had been governed by horizontal moisture advection up to that point (Fig. 4). In primary events, the origin of the $\chi$ anomalies are not related to a prior MJO event, but instead can be traced to South America $\left(\sim 300^{\circ}\right.$ longitude). A similar result was found by Sakaeda and Roundy $(2015,2016)$, who found that an equatorial wave signal reminiscent of a Kelvin wave is excited in South America, which then propagates eastward toward the Indian Ocean. The dry adiabatic lifting associated with this wave coincides with the increase in moisture over the Indian Ocean, suggesting that it acts to maintain it. 


\section{MJO initiation over the Indian Ocean}

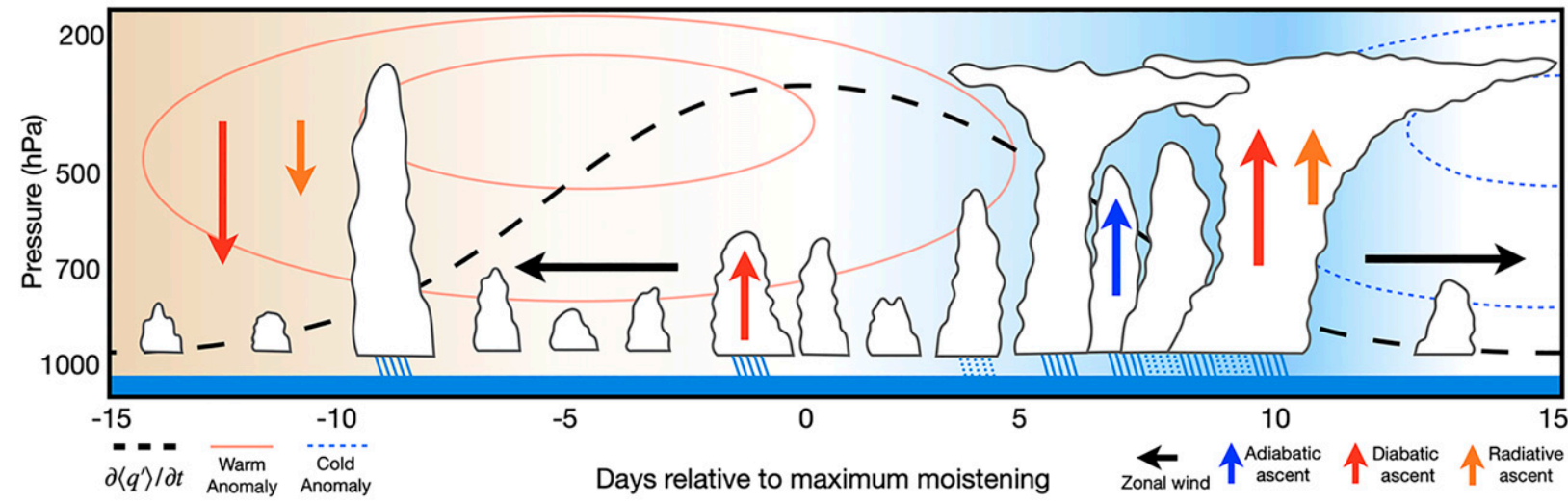

FIG. 9. Schematic describing the temporal evolution of moistening process of a composite MJO initiation event over the Indian Ocean. Arrows depict the horizontal wind and the adiabatic, diabatic, and radiative vertical velocities with colors indicated by the legend. The dashed black line denotes the moisture tendency. Solid red contours denote warm anomalies while dashed blue contours depict cold anomalies. The light blue background denotes a humid troposphere while the light brown background denotes a dry troposphere.

Although moistening by adiabatic lifting plays a role in both types of initiation events, this process is nearly twice as strong in successive initiation events, likely due to the strength of the circumnavigating signal, as suggested by the $\chi$ contours in Fig. 2 .

While we assume that dry adiabatic lifting comes from the circumnavigating signal, we do not discard the possibility that that horizontal temperature advection also plays a role in forcing adiabatic lifting since previous studies have indicated this process plays an important role in MJO initiation (Zhao et al. 2013; Li et al. 2015).

In spite of the difference in origin and magnitude of the dry adiabatic lifting, the evolution of primary and successive events is broadly similar, and thus Fig. 9 can be used to summarize both types of initiation. Moistening of the Indian Ocean begins as a result of anomalous horizontal moisture advection, followed by moistening by adiabatic lifting. Once convection develops, both dry adiabatic lifting and radiative heating maintain the moisture anomalies from dissipating from increased condensation from the enhanced deep convection.

Because the ERA-I data contain a substantial residual in the moisture budget analysis, we compared the results from ERA-I with sounding-based data from DYNAMO. While the two datasets qualitatively agree on the role of the moist processes in MJO evolution, they also exhibit marked differences. Many of these differences are attributed to the compositing method. The ERA-I results are based on composites that span the equatorial Indian Ocean $\left(10^{\circ} \mathrm{N}-10^{\circ} \mathrm{S}, 60^{\circ}-100^{\circ} \mathrm{E}\right)$, while the DYNAMO data are limited to the northern sounding array. The differences attributed to compositing method include the overall magnitude of the processes, the role of surface fluxes in MJO maintenance, and the projection of the moisture tendency on the moisture anomalies. We discuss these differences in further detail in appendix B. However, several differences between ERA-I and DYNAMO cannot be explained by choice of methods. For example, vertical MSE advection by diabatic heating plays a primary role in MJO evolution in the DYNAMO data, while its contribution is negligible in ERA-I. Furthermore, dry adiabatic lifting is not found to play a significant role in the moistening prior to the onset of convection in the DYNAMO data (Fig. 8b), while it is the second largest contributor in ERA-I. It is possible that these differences can be partly attributed to the budget residual in ERA-I and the fact that ERA-I is a composite of multiple MJO events while the DYNAMO data only contain three events. However, more work is needed to further understand the disagreements between the datasets.

The results from both ERA-I and DYNAMO data exhibit some similarities to the findings of Powell (2016). In his study, adiabatic motions were suggested to play a significant role in the temperature tendency associated with initiation, which played a key role in the moistening of the free troposphere during a single MJO initiation. We note, however, that Powell (2016) defined adiabatic lifting as the vertical DSE advection by the total vertical velocity, including the vertical velocities that balance the diabatic heating. Furthermore, his thermodynamic budget is evaluated on data with mean fields retained, while our budget is filtered to retain intraseasonal variability. In spite of these differences, examination of Figs. 16 and 17 in Powell (2016) shows a cooling of the troposphere during MJO initiation, consistent with the adiabatic lifting that is found in this study.

While our results suggest a chronological order in the processes that lead to MJO initiation, our results do not invalidate different views on MJO initiation. It is possible that extratropical forcing could lead to dry adiabatic lifting over the Indian Ocean, or that extratropical motions can excite the wave signal that leads to primary initiation (Ray and Zhang 2010; Sakaeda and Roundy 2016). Additionally, the horizontal moisture advection can come from intraseasonal circulation features (Zhao et al. 2013), or from higher-frequency waves, as suggested by Takasuka et al. (2019) and (Wei et al. 2019). Future work should examine in more detail the potential diversity in the atmospheric conditions that lead to MJO initiation, as also suggested by Li et al. (2015).

In summary, our results reveal that vertical moisture advection from adiabatic lifting plays an important role in the late stages of primary and successive MJO initiation. Because dry adiabatic lifting is intrinsically related to temperature tendencies in large-scale propagating waves, these results indicate that small departures 


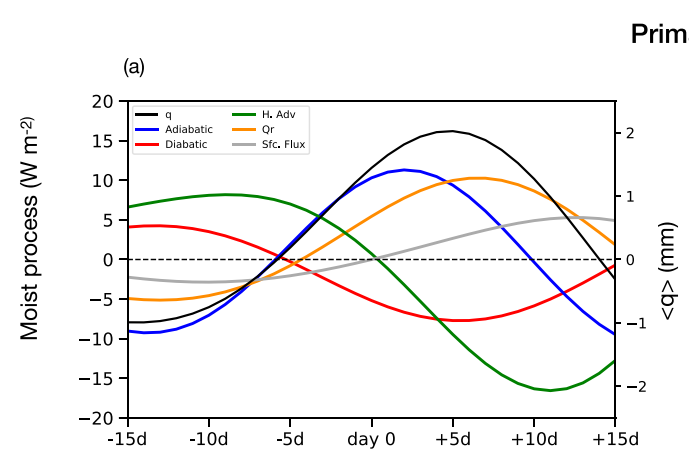

\section{Primary Events}

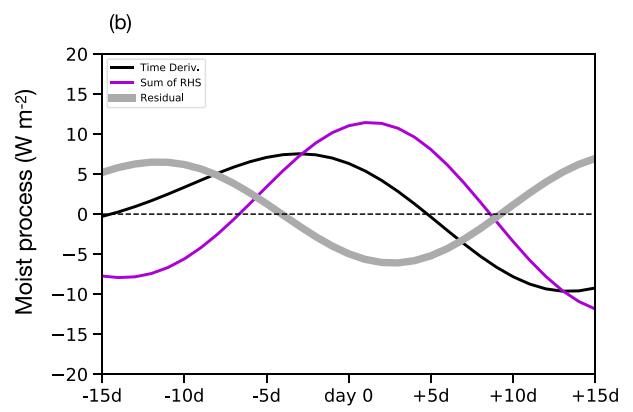

Successive Events

(c)

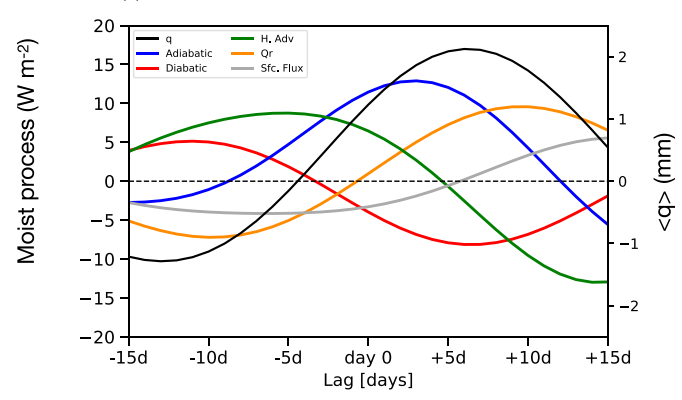

(d)

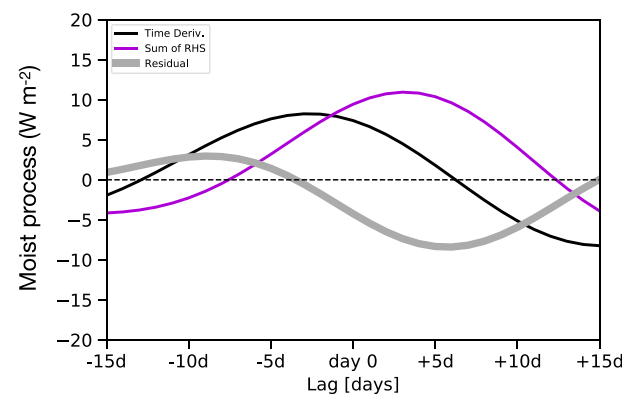

FIG. B1. As in Fig. 5, but averaged over the domain $3^{\circ} \mathrm{N}-3^{\circ} \mathrm{S}, 70^{\circ}-75^{\circ} \mathrm{E}$.

from WTG balance may play an important role in the MJO. Thus, the conventional WTG approximation, which neglects small temperature fluctuations in the free troposphere, is not adequate for examining MJO initiation. While both the ERA-I and DYNAMO data show that dry adiabatic lifting plays an important role at this time, they disagree on whether dry adiabatic lifting plays a major in moistening the troposphere prior to the onset of convection. More work is needed to further quantify the importance of dry adiabatic lifting during MJO initiation. Future work should also examine the role of dry adiabatic motions in the evolution of the MJO and other tropical motion systems. An improved understanding of such processes could lead to improvements in the modeling and prediction of tropical motions and its impact on the global climate system.

Acknowledgments. This work was supported by the University of Wisconsin Startup package. ÁFA and VCM were also supported by the National Science Foundation (NSF) Grant AGS1841559. SWP acknowledges support from the Office of Naval Research under Grant N0001421WX01472. ERA-Interim data, including the diabatic heating field $Q_{1}$, were obtained by ÁFA from Dargan Frierson at the University of Washington.

\section{APPENDIX A}

\section{Thermodynamic Energy Equation under the Relaxed WTG Approximation}

The thermodynamic energy equation for an ideal gas may be written as

$$
C_{p} \frac{D T}{D t}-\frac{1}{\rho} \frac{D p}{D t}=Q_{1}
$$

where $\rho$ is the density of air, and $D / D t$ is the material derivative. In isobaric coordinates, the material derivative and the vertical velocity are written as

$$
\begin{aligned}
\frac{D}{D t} & =\frac{\partial}{\partial t}+\mathbf{v} \cdot \nabla+\omega \frac{\partial}{\partial p}, \\
\frac{D p}{D t} & =\omega .
\end{aligned}
$$

We can use hydrostatic balance

$$
\frac{\partial \Phi}{\partial p}=-\frac{1}{\rho}
$$

to eliminate $\rho$ from Eq. (A1), from which we can obtain Eq. (1a). Equation (1a) is reminiscent of the commonly used DSE equation (Yanai et al. 1973; Inoue and Back 2015). The DSE equation can be obtained from Eq. (1a) under the assumption that horizontal and temporal fluctuations in the geopotential are small. Thus, the DSE equation is an approximation of the isobaric thermodynamic equation.

\section{APPENDIX B}

\section{Sensitivity of ERA-I Results to Choice of Domain}

In the main text we compared the intraseasonal columnintegrated moisture budget of ERA-I and the DYNAMO northern sounding array during MJO initiation. While the two 


\section{Primary Events}

(a) Contribution to $<q^{\prime}>$ evolution (nondim)

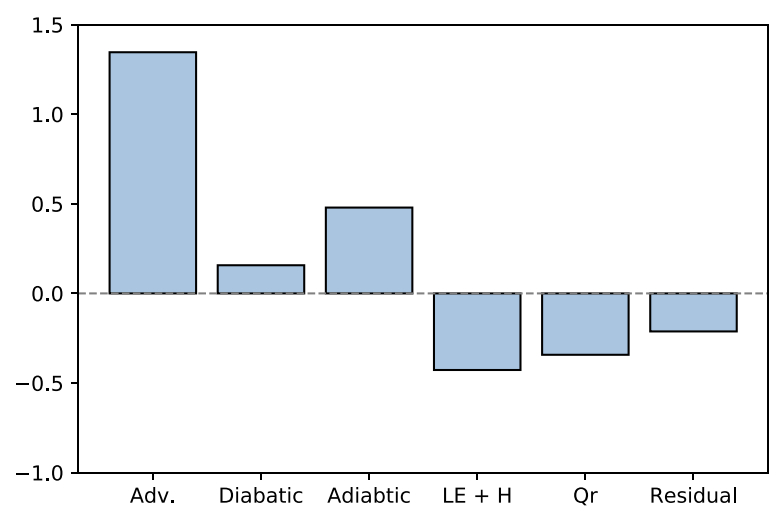

(b) Contribution to $\left\langle q^{\prime}>\right.$ maintenance $\left(\right.$ day $\left.^{-1}\right)$

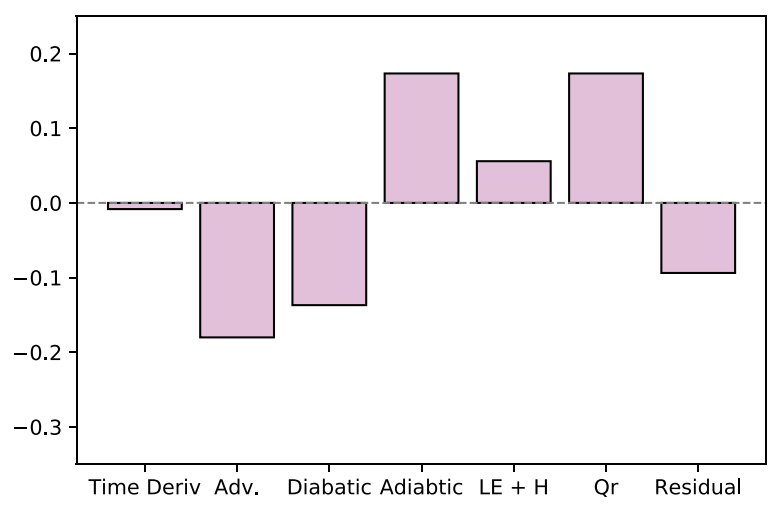

\section{Successive Events}

(c)

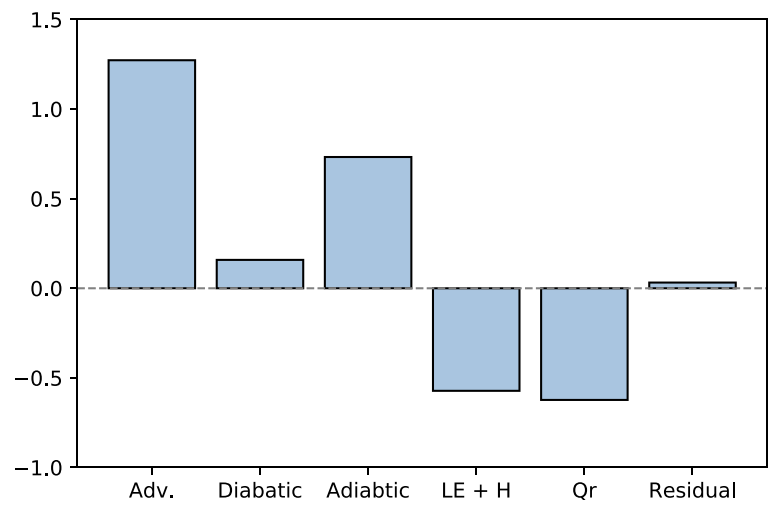

(d)

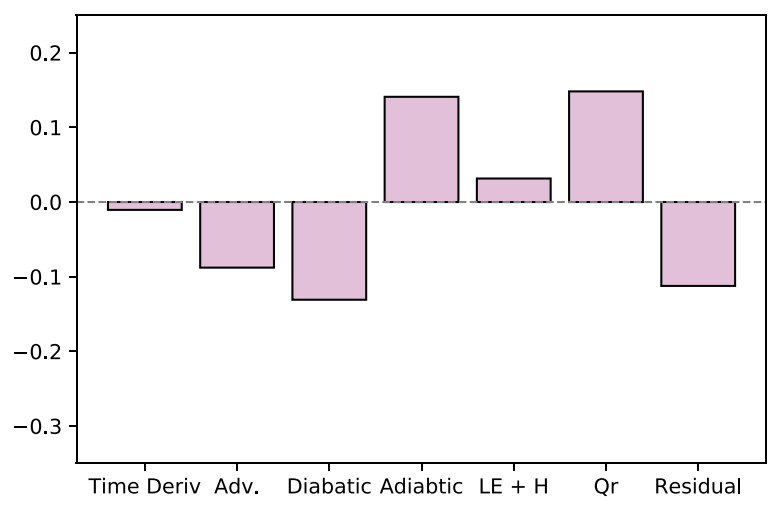

FIG. B2. As in Fig. 6, but averaged over the domain $3^{\circ} \mathrm{N}-3^{\circ} \mathrm{S}, 70^{\circ}-75^{\circ} \mathrm{E}$.

datasets qualitatively agreed on which processes contributed to MJO maintenance and evolution, they also exhibited some marked differences. One difference is that the moist processes over the DYNAMO sounding array are nearly an order of magnitude larger than the ERA-I composites. Furthermore, the moisture tendency projects negatively to the moisture anomalies in the DYNAMO sounding data, implying damping, while it projects positively in the ERA-I data, implying growth. In this section we will show that some of the differences are attributed to the choice of averaging domain in Figs. 5 and 6.

Figure B1 shows the ERA-I budget terms from Fig. 5 in the main text but averaged over a smaller domain surrounding the DYNAMO sounding array location. By choosing a smaller domain we observe that the magnitude of the different terms compares more favorably to those from the DYNAMO array. However, they are still roughly half the amplitude. This difference may be accounted for by the number of events that are composited in the ERA-I data (25 primary and 52 successive) versus the three events that were captured during DYNAMO.
In Fig. B1 we also see that the projection of the moisture tendency on the moisture anomalies is no longer positive. The positive projection of the moisture anomalies in ERA-I is due to a correlation between the moisture and moisture tendency over the eastern Indian Ocean $\left(80^{\circ}-100^{\circ} \mathrm{E}\right)$, to the east of the DYNAMO array. Thus, the moisture anomalies are likely growing during MJO initiation.

Looking at the progression of the budget terms in Fig. B1 averaged over the DYNAMO domain, the magnitude of $-\left\langle\omega_{a} \partial_{p} L q\right\rangle$ is comparable to those seen in Fig. 7 in the main text and has a similar progression. A notable difference between ERA-I and DYNAMO data is the magnitude of $-\left\langle\omega_{Q} \partial_{p} m\right\rangle$, which is 4 times larger in the DYNAMO data. This is likely a result of a misrepresentation of convection ERA-I during MJO initiation, which is also related to the residual seen in Figs. B1b and B1c. It is clear that the adiabatic term in both datasets plays a role in offsetting the drying due to diabatic heating and without it the MJO would be damped.

In Fig. B2 the contribution to the evolution and maintenance of moisture anomalies during MJO initiation can be visualized. As seen in the DYNAMO data projections (Fig. 8b) the time 
derivative is projecting negatively implying drying; this same signal can be seen in ERA-I when analyzing a smaller domain. The largest difference that remains is the sign of $-\left\langle\omega_{a} \partial_{p} L q\right\rangle$ in the evolution of moisture anomalies.

\section{REFERENCES}

Adames, Á. F., 2017: Precipitation budget of the Madden-Julian oscillation. J. Atmos. Sci., 74, 1799-1817, https://doi.org/ 10.1175/JAS-D-16-0242.1.

_ , and J. M. Wallace, 2014: Three-dimensional structure and evolution of the MJO and its relation to the mean flow. J. Atmos. Sci., 71, 2007-2026, https://doi.org/10.1175/JAS-D13-0254.1.

— , and E. D. Maloney, 2021: Moisture mode theory's contribution to advances in our understanding of the Madden-Julian oscillation and other tropical disturbances. Curr. Climate Change Rep., 7, 72-85, https://doi.org/10.1007/s40641-021-00172-4.

— S. W. Powell, F. Ahmed, V. C. Mayta, and J. D. Neelin, 2021: Tropical precipitation evolution in a buoyancy-budget framework. J. Atmos. Sci., 78, 509-528, https://doi.org/10.1175/JAS-D20-0074.1.

Andersen, J. A., and Z. Kuang, 2012: Moist static energy budget of MJO-like disturbances in the atmosphere of a zonally symmetric aquaplanet. J. Climate, 25, 2782-2804, https://doi.org/ 10.1175/JCLI-D-11-00168.1.

Bellenger, H., K. Yoneyama, M. Katsumata, T. Nishizawa, K. Yasunaga, and R. Shirooka, 2015: Observation of moisture tendencies related to shallow convection. J. Atmos. Sci., 72, 641-659, https://doi.org/10.1175/JAS-D-14-0042.1.

Chen, X., and F. Zhang, 2019: Relative roles of preconditioning moistening and global circumnavigating mode on the MJO convective initiation during DYNAMO. Geophys. Res. Lett., 46, 1079-1087, https://doi.org/10.1029/2018GL080987.

Chikira, M., 2014: Eastward-propagating intraseasonal oscillation represented by Chikira-Sugiyama cumulus parameterization. Part II: Understanding moisture variation under weak temperature gradient balance. J. Atmos. Sci., 71, 615-639, https:// doi.org/10.1175/JAS-D-13-038.1.

Ciesielski, P. E., and Coauthors, 2014: Quality-controlled upper-air sounding dataset for DYNAMO/CINDY/AMIE: Development and corrections. J. Atmos. Oceanic Technol., 31, 741-764, https:// doi.org/10.1175/JTECH-D-13-00165.1.

Dee, D. P., and Coauthors, 2011: The ERA-Interim reanalysis: Configuration and performance of the data assimilation system. Quart. J. Roy. Meteor. Soc., 137, 553-597, https://doi.org/ 10.1002/qj.828.

Duchon, C. E., 1979: Lanczos filtering in one and two dimensions. J. Appl. Meteor., 18, 1016-1022, https://doi.org/10.1175/15200450(1979)018<1016:LFIOAT>2.0.CO;2.

Feng, Z., S. A. McFarlane, C. Schumacher, S. Ellis, J. Comstock, and N. Bharadwaj, 2014: Constructing a merged cloud-precipitation radar dataset for tropical convective clouds during the DYNAMO/AMIE experiment at Addu Atoll. J. Atmos. Oceanic Technol., 31, 1021-1042, https://doi.org/10.1175/ JTECH-D-13-00132.1.

Haertel, P., K. Straub, and A. Budsock, 2015: Transforming circumnavigating Kelvin waves that initiate and dissipate the Madden-Julian oscillation. Quart. J. Roy. Meteor. Soc., 141, 1586-1602, https://doi.org/10.1002/qj.2461.

Hendon, H. H., and M. L. Salby, 1994: The life cycle of the MaddenJulian oscillation. J. Atmos. Sci., 51, 2225-2237, https://doi.org/ 10.1175/1520-0469(1994)051<2225:TLCOTM>2.0.CO;2.
Huffman, G. J., and Coauthors, 2007: The TRMM Multisatellite Precipitation Analysis (TMPA): Quasi-global, multiyear, combinedsensor precipitation estimates at fine scales. J. Hydrometeor., 8, 3855, https://doi.org/10.1175/JHM560.1.

Inoue, K., and L. Back, 2015: Column-integrated moist static energy budget analysis on various time scales during TOGA COARE. J. Atmos. Sci., 72, 1856-1871, https://doi.org/ 10.1175/JAS-D-14-0249.1.

_- Á. F. Adames, and K. Yasunaga, 2020: Vertical velocity profiles in convectively coupled equatorial waves and MJO: New diagnoses of vertical velocity profiles in the wavenumberfrequency domain. J. Atmos. Sci., 77, 2139-2162, https:// doi.org/10.1175/JAS-D-19-0209.1.

Janiga, M. A., and C. Zhang, 2016: MJO moisture budget during DYNAMO in a cloud-resolving model. J. Atmos. Sci., 73, 2257-2278, https://doi.org/10.1175/JAS-D-14-0379.1.

Jiang, X., and Coauthors, 2020: Fifty years of research on the Madden-Julian oscillation: Recent progress, challenges, and perspectives. J. Geophys. Res. Atmos., 125, e2019JD030911, https://doi.org/10.1029/2019JD030911.

Johnson, R. H., P. E. Ciesielski, J. H. Ruppert, and M. Katsumata, 2015: Sounding-based thermodynamic budgets for DYNAMO. J. Atmos. Sci., 72, 598-622, https://doi.org/10.1175/JAS-D-140202.1.

Kikuchi, K., and Y. N. Takayabu, 2003: Equatorial circumnavigation of moisture signal associated with the Madden-Julian oscillation (MJO) during boreal winter. J. Meteor. Soc. Japan, 81, 851-869, https://doi.org/10.2151/jmsj.81.851.

Kiladis, G. N., K. H. Straub, and P. T. Haertel, 2005: Zonal and vertical structure of the Madden-Julian oscillation. J. Atmos. Sci., 62, 2790-2809, https://doi.org/10.1175/JAS3520.1.

, J. Dias, K. H. Straub, M. C. Wheeler, S. N. Tulich, K. Kikuchi, K. M. Weickmann, and M. J. Ventrice, 2014: A comparison of OLR and circulation-based indices for tracking the MJO. Mon. Wea. Rev., 142, 1697-1715, https://doi.org/10.1175/MWR-D-13-00301.1.

Kim, D., M.-I. Lee, D. Kim, S. D. Schubert, D. E. Waliser, and B. Tian, 2014b: Representation of tropical subseasonal variability of precipitation in global reanalyses. Climate Dyn., $\mathbf{4 3}$, 517-534, https://doi.org/10.1007/s00382-013-1890-x.

Kim, H., P. J. Webster, V. E. Toma, and D. Kim, 2014: Predictability and prediction skill of the MJO in two operational forecasting systems. J. Climate, 27, 5364-5378, https://doi.org/10.1175/JCLID-13-00480.1.

_, F. Vitart, and D. E. Waliser, 2018: Prediction of the MaddenJulian oscillation: A review. J. Climate, 31, 9425-9443, https:// doi.org/10.1175/JCLI-D-18-0210.1.

Kiranmayi, L., and E. D. Maloney, 2011: Intraseasonal moist static energy budget in reanalysis data. J. Geophys. Res., 116, https:// doi.org/10.1029/2011JD016031.

Li, T., C. Zhao, P.-C. Hsu, and T. Nasuno, 2015: MJO initiation processes over the tropical Indian Ocean during DYNAMO/ CINDY2011. J. Climate, 28, 2121-2135, https://doi.org/10.1175/ JCLI-D-14-00328.1.

Liebmann, B., and C. A. Smith, 1996: Description of a complete (interpolated) outgoing longwave radiation dataset. Bull. Amer. Meteor. Soc., 77, 1275-1277, https://doi.org/10.1175/1520-0477-77.6.1274.

Madden, R. A., and P. R. Julian, 1971: Detection of a 40-50 day oscillation in the zonal wind in the tropical Pacific. J. Atmos. Sci., 28, 702-708, https://doi.org/10.1175/15200469(1971)028<0702:DOADOI > 2.0.CO;2.

- and - 1972: Description of global-scale circulation cells in the tropics with a 40-50 day period. J. Atmos. Sci., 29, 1109-1123, https:// doi.org/10.1175/1520-0469(1972)029<1109:DOGSCC>2.0.CO;2. 
Mapes, B. E., 1997: Mutual adjustment of mass flux and stratification profiles. The Physics and Parameterization of Moist Atmospheric Convection, R. K. Smith, Ed., NATO ASI Series, Vol. 505, Springer, 399-411, https://doi.org/10.1007/978-94015-8828-7_16.

_, and J. T. Bacmeister, 2012: Diagnosis of tropical biases and the MJO from patterns in the MERRA analysis tendency fields. J. Climate, 25, 6202-6214, https://doi.org/10.1175/JCLID-11-00424.1.

— , S. Tulich, J. Lin, and P. Zuidema, 2006: The mesoscale convection life cycle: Building block or prototype for large-scale tropical waves? Dyn. Atmos. Oceans, 42 (1), 3-29, https:// doi.org/10.1016/j.dynatmoce.2006.03.003.

Matthews, A. J., 2008: Primary and successive events in the Madden-Julian oscillation. Quart. J. Roy. Meteor. Soc., 134, 439-453, https://doi.org/10.1002/qj.224.

Mayta, V. C., G. N. Kiladis, J. Dias, P. L. S. Dias, and M. Gehne, 2021: Convectively coupled Kelvin waves over tropical South America. J. Climate, 34, 6531-6547, https://doi.org/10.1175/ JCLI-D-20-0662.1.

Mei, S., T. Li, and W. Chen, 2015: Three-type MJO initiation processes over the western equatorial Indian Ocean. $A d v$. Atmos. Sci., 32, 1208-1216, https://doi.org/10.1007/s00376-0154201-0.

Milliff, R. F., and R. A. Madden, 1996: The existence and vertical structure of fast, eastward-moving disturbances in the equatorial troposphere. J. Atmos. Sci., 53, 586-597, https://doi.org/ 10.1175/1520-0469(1996)053<0586:TEAVSO > 2.0.CO;2.

Nasuno, T., T. Li, and K. Kikuchi, 2015: Moistening processes before the convective initiation of Madden-Julian oscillation events during the CINDY2011/DYNAMO period. Mon. Wea. Rev., 143, 622-643, https://doi.org/10.1175/MWR-D-14-00132.1.

Powell, S. W., 2016: Updraft buoyancy within and moistening by cumulonimbi prior to $\mathrm{MJO}$ convective onset in a regional model. J. Atmos. Sci., 73, 2913-2934, https://doi.org/10.1175/ JAS-D-15-0326.1.

_- 2017: Successive MJO propagation in MERRA-2 reanalysis. Geophys. Res. Lett., 44, 5178-5186, https://doi.org/10.1002/ 2017GL073399.

— , and R. A. Houze Jr., 2015: Effect of dry large-scale vertical motions on initial MJO convective onset. J. Geophys. Res. Atmos., 120, 4783-4805, https://doi.org/10.1002/2014JD022961.

Ray, P., and C. Zhang, 2010: A case study of the mechanics of extratropical influence on the initiation of the Madden-Julian oscillation. J. Atmos. Sci., 67, 515-528, https://doi.org/10.1175/ 2009JAS3059.1.

Raymond, D., and X. Zeng, 2005: Modeling tropical atmospheric convection in the context of the weak temperature gradient approximation. Quart. J. Roy. Meteor. Soc., 131, 1301-1320, https://doi.org/10.1256/qj.03.97.

Ren, P., D. Kim, M.-S. Ahn, D. Kang, and H.-L. Ren, 2021: Intercomparison of MJO column moist static energy and water vapor budget among six modern reanalysis products. J. Climate, 34, 2977-3001, https://doi.org/10.1175/JCLI-D-200653.1.

Ruppert, J. H., and R. H. Johnson, 2015: Diurnally modulated cumulus moistening in the preonset stage of the MaddenJulian oscillation during DYNAMO. J. Atmos. Sci., 72, 16221647, https://doi.org/10.1175/JAS-D-14-0218.1.
Sakaeda, N., and P. E. Roundy, 2015: The development of uppertropospheric wind over the Western Hemisphere in association with MJO convective initiation. J. Atmos. Sci., 72, 3138-3160, https://doi.org/10.1175/JAS-D-14-0293.1.

- , and — 2016: The development of upper-tropospheric geopotential height anomaly in the Western Hemisphere during MJO convective initiations. Quart. J. Roy. Meteor. Soc., 142, 942-956, https://doi.org/10.1002/qj.2696.

Sobel, A. H., and D. Kim, 2012: The MJO-Kelvin wave transition. Geophys. Res. Lett., 39, 2012GL053380, https://doi.org/10.1029/ 2012GL053380.

— J. Nilsson, and L. M. Polvani, 2001: The weak temperature gradient approximation and balanced tropical moisture waves. J. Atmos. Sci., 58, 3650-3665, https://doi.org/10.1175/15200469(2001)058<3650:TWTGAA > 2.0.CO;2.

- S. Wang, and D. Kim, 2014: Moist static energy budget of the MJO during DYNAMO. J. Atmos. Sci., 71, 4276-4291, https:// doi.org/10.1175/JAS-D-14-0052.1.

Straub, K. H., 2013: MJO initiation in the real-time multivariate MJO index. J. Climate, 26, 1130-1151, https://doi.org/10.1175/ JCLI-D-12-00074.1.

Takasuka, D., M. Satoh, and S. Yokoi, 2019: Observational evidence of mixed Rossby-gravity waves as a driving force for the MJO convective initiation and propagation. Geophys. Res. Lett., 46, 5546-5555, https://doi.org/10.1029/2019GL083108.

Wei, Y., M. Mu, H.-L. Ren, and J.-X. Fu, 2019: Conditional nonlinear optimal perturbations of moisture triggering primary MJO initiation. Geophys. Res. Lett., 46, 3492-3501, https:// doi.org/10.1029/2018GL081755.

Wolding, B., 2013: Moist static energy and the Madden-Julian oscillation: Understanding initiation, maintenance and propagation through the application of novel diagnostics. Ph.D. thesis, Colorado State University, $134 \mathrm{pp}$.

— E. D. Maloney, and M. Branson, 2016: Vertically resolved weak temperature gradient analysis of the Madden-Julian oscillation in SP-CESM. J. Adv. Model. Earth Syst., 8, 15861619, https://doi.org/10.1002/2016MS000724.

Yanai, M., S. Esbensen, and J.-H. Chu, 1973: Determination of bulk properties of tropical cloud clusters from large-scale heat and moisture budgets. J. Atmos. Sci., 30, 611-627, https://doi.org/ 10.1175/1520-0469(1973)030<0611:DOBPOT >2.0.CO;2.

Yokoi, S., 2015: Multireanalysis comparison of variability in column water vapor and its analysis increment associated with the Madden-Julian oscillation. J. Climate, 28, 793-808, https:// doi.org/10.1175/JCLI-D-14-00465.1.

Yong, Y., and J. Mao, 2016: Mechanistic analysis of the suppressed convective anomaly precursor associated with the initiation of primary MJO events over the tropical Indian Ocean. Climate Dyn., 46, 779-795, https://doi.org/10.1007/ s00382-015-2612-3.

Zhang, C., 2005: Madden-Julian oscillation. Rev. Geophys., 43, RG2003, https://doi.org/10.1029/2004RG000158.

_ 2013: Madden-Julian oscillation: Bridging weather and climate. Bull. Amer. Meteor. Soc., 94, 1849-1870, https://doi.org/ 10.1175/BAMS-D-12-00026.1.

Zhao, C., T. Li, and T. Zhou, 2013: Precursor signals and processes associated with MJO initiation over the tropical Indian Ocean. J. Climate, 26, 291-307, https://doi.org/10.1175/JCLI-D-1200113.1. 